\section{INTERACTION OF AN \\ ISOLATED SPRINKLER \\ SPRAY AND A TWO-LAYER \\ COMPARTMENT FIRE \\ ENVIRONMENT}

Leonard Y. Cooper

U.S. DEPARTMENT OF COMMERCE Natlonal Institute of Standards and Technology

Bullding and Fire Research Laboratory Gaithersbure, MD 20899

Sponsored by:

American Archltectural Manufacturers Assoc. Research Foundation 2700 River Road, Suite 118 Des Plaines, IL 60018

U.S. DEPARTMENT OF COMMERCE Robert A. Mosbacher, Secretary NATIONAL INSTITUTE OF STANDARDS AND TECHNOLOGY

John W. Lyons, Director 



\title{
INTERACTION OF AN \\ ISOLATED SPRINKLER \\ SPRAY AND A TWO-LAYER \\ COMPARTMENT FIRE \\ ENVIRONMENT
}

\section{Leonard Y. Cooper}

\author{
U.S. DEPARTMENT OF COMMERCE \\ National Institute of Standards \\ and Technology \\ Building and Fire Research Laboratory \\ Gaithersburg, MD 20899
}

Sponsored by:

American Architectural Manufacturers AssoG Research Foundation

2700 River Road, Suite 118

Des Plaines, IL 60018

May 1991

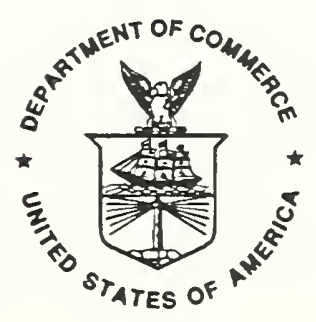

U.S. DEPARTMENT OF COMMERCE Robert A. Mosbacher, Secretary MATONAL INSTITUTE OF STANDARDS AND TECHNOLOGY

John $W$. Lyons, Director 

TABLE OF CONTENTS. . . . . . . . . . . . . . . . . . . . . . . . . . . . . 1

LIST OF FIGURES. . . . . . . . . . . . . . . . . . . . . . . . . . . . . . 1

ABSTRACT . . . . . . . . . . . . . . . . . . . . . . . . . . . . . 1

INTRODUCTION . . . . . . . . . . . . . . . . . . . . . . . . . . . . . . 2

Qualitative Description of the Spray/Layer Interactions . . . . . 2

The Objective . . . . . . . . . . . . . . . . . . . . . . . . . . . 5

Specifying the Two-Layer Fire Environment . . . . . . . . . . . . . 5

FORMULATION OF THE PROBLEM FOR THE FLOWS IN THE SPRAY CONE ENVELOPE . . 5

Fragmentation of the Nozzle Flow - The Spray Cone Envelope . . . . . 5

Drag Forces Between the Drops and the Jet Gases . . . . . . . . . . 6

Heat and Mass Transfer Between the Drops and the Jet Gases . . . . . 8

Problem Variables and Parameters . . . . . . . . . . . . . . . . . . 9

Conservation Equations for the Spray Envelope . . . . . . . . . . . . . 10

The Generalized Equation Set for $\mathrm{u}_{\mathrm{p}}^{*}, \mathrm{u}_{\mathrm{s}}^{*}, \mathrm{~T}_{\mathrm{s}}^{*}, \dot{\mathrm{Q}}_{\mathrm{d}}^{*}, \dot{\mathrm{M}}^{*}$, and $\dot{\mathrm{M}}_{\mathrm{d}} . . . .15$

SOLVING THE PROBLEM FOR THE SPRAY CONE ENVELOPE . . . . . . . . . . . . . 18

The Solution Near Elevations Where $u_{s}^{*}=0$. . . . . . . . . . . . . 18

The Solution Near $\mathrm{x}^{*}=\mathrm{x}_{\mathrm{w}}^{*}$. . . . . . . . . . . . . . . . . . . . . 18

Continuing the Solution to Arbitrary $x^{\star}$. . . . . . . . . . . . . . 18

ICOND 2-6 Scenarios: Identifying the Value of $x_{8}<x_{\mathrm{F}_{\text {LOOR }}}$, When It

Exists, and Determining the Solution Variables in the Range

$\mathrm{x}_{\mathrm{INT}}^{*}<\mathrm{x}^{*} \leq \mathrm{x}_{\mathrm{FLOOR}}^{*}$. . . . . . . . . . . . . . . . . . . . . . . 19

The Solution For $x^{\star}>x_{\delta}$. . . . . . . . . . . . . . . . . . . . . 20

Summary of the Solution Procedure . . . . . . . . . . . . . . . . 21

CALCULATING THE LOWER LAYER ENTRAINMENT RATE BETWEEN THE INTERFACE AND

$x_{o}$ IN A FIGURE la SCENARIO . . . . . . . . . . . . . . . . . . . . . 21

Results from a Related Problem: Jets and Plumes with Reversed,

Purely Buoyant Body Forces . . . . . . . . . . . . . . . . . . 21

Using the Purely-Buoyant-Flow Results to Predict $\dot{\mathrm{M}}_{\mathrm{ENT}}$ Due to the

Sprinkler-Driven Gas Jet of the Figure la Scenario . . . . . . 22

THE RATES OF FLOW OF MASS, ENTHALPY AND PRODUCTS OF COMBUSTION TO THE

UPPER AND LOWER LAYERS . . . . . . . . . . . . . . . . . . . . . . . 24

ICOND 3 or 4 Scenarios. . . . . . . . . . . . . . . . . . . . . . . . . . . . 24

ICOND 2, 5, or 6 Scenarios . . . . . . . . . . . . . . . . . . 25

The ICOND 1 Scenario... . . . . . . . . . . . . . . . . 25

EXAMPLE CALCULATiONS . . . . . . . . . . . . . . . . . . . . . . . . . . . 26

Comparisons of Model Calculations With Experiments and Calcula-

tions of [1] and [4] for a Spray in an Ambient Temperature

Environment . . $\cdot \cdot \cdot \cdot \cdot \cdot \cdot \cdot \cdot \cdot \cdot \cdot \cdot \cdot \cdot \cdot \cdot \cdot \cdot \cdot \cdot \cdot \cdot \cdot \cdot \cdot \cdot \cdot$

Simulated Interactions Between Two-Layer Fire Environments and a Rockwood T-4 Spray Nozzle Flow . . . . . . . . . . . 26 
Summary of the Example Calculations - Ceiling Venting to Enhance the Effectiveness of Sprinkler Systems . . . . . . . . . . . 28

USING THE SPRINKLER/LAYER INTERACTION MODEL IN LAVENT . . . . . . . . . . . 29

SUMMARY AND CONCLUSIONS . . . . . . . . . . . . . . . . . . . . . . . 29

ACKNOWLEDGEMENT . . . . . . . . . . . . . . . . . . . . . . . . . . . . . . . . 30

NOMENCLATURE . . . . . . . . . . . . . . . . . . . . . . . . . . 31

REFERENCES . . . . . . . . . . . . . . . . . . . . . . . . 35 


\section{LIST OF FIGURES}

Page

Figure 1. The three generic scenarios for interaction of an operating sprinkler and a two-layer fire environment. . . . . . . . . . 36

Figure 2. Flow conditions of Figure la: ICOND 3 and 4.......... 37

Figure 3. Flow conditions of Figure Ib: ICOND 2, 5, or 6. . . . . . . 38

Figure 4. Procedure for solving Eqs. (51)-(65) for $x_{\mathrm{W}}^{\star}<\mathrm{x}^{\star} \leq \mathrm{x}_{\mathrm{FLOOR}}^{*} \cdot$. 39

Figure 5. Experimental studies of jets and plumes with reversed, purely buoyant body forces: a) to determine $\delta_{p}[6]$; and b) to determine $\dot{\mathrm{M}}_{\mathrm{ENT}}[$ [7] . . . . . . . . . . . . . . . . . . . . . . 40

Figure 6. Predictions of $\dot{\mathrm{M}}_{\mathrm{ENT}}$ and $\mathrm{x}_{\delta}$ vs interface elevation for a spray nozzle operating in a two-layer fire environment with a $600 \mathrm{~K}$ upper layer and a $293 \mathrm{~K}$ lower layer. . . . . . . . . . . . . . 41

Figure 7. Predictions of $\dot{\mathrm{M}}_{\mathrm{ENT}}$ and $\mathrm{x}_{\delta}$ vs upper layer temperature for a spray nozzle operating above a two-layer fire environment with a $5 \mathrm{~m}$ thick upper layer and a 293K lower layer. . . . . . . . . . . 42 



\title{
THE INTERACTION OF AN ISOLATED SPRINKLER SPRAY AND A TWO-LAYER COMPARTMENT FIRE ENVIRONMENT
}

\author{
Leonard Y. Cooper \\ National Institute of Standards and Technology \\ Gaithersburg, MD 02899
}

\begin{abstract}
The overall objective of this work, which was sponsored by the American Architectural Manufacturers Association (AAMA) Research Foundation, was to develop a model to predict the interaction of sprinklers and compartment-firegenerated smoke layers, and to include the effect in an enhanced version of the compartment fire model computer code LAVENT (Link Actuated Vents). The resulting new computer code would be capable of simulating the combined effects of sprinklers and ceiling vents on time-dependent compartment fire environments. The present work is a report of the sprinkler/smoke-layerinteraction part of the problem.
\end{abstract}

A mathematical model is developed to simulate the interaction of an isolated operating sprinkler and a two-layer fire environment under arbitrary conditions of sprinkler-nozzle elevation, and upper- and lower-layer thickness and temperature. The sprinkler is characterized by water flow rate, nozzle diameter, and three other measurable device parameters related to: drop size of the water flow after nozzle stream fragmentation, momentum of the water flow after stream fragmentation, and shape of the sprinkler spray.

The model takes account of all effects of the sprinkler spray as it entrains, drives downward (by aerodynamic drag on the spray drops), humidifies, and cools (by drop evaporation) gases from both the high temperature upper layer and the relatively cooler lower layer. For example, depending on conditions, a downward moving spray cone gas jet penetrates the layer interface and is subject there to a net upward or downward force. When the net force is upward and strong enough, the jet gases are driven out of the spray cone and buoyed back up into the upper layer together with entrained lower layer gases. The model provides a means of predicting the flow rates of mass, enthalpy, products of combustion, and evaporated water to each of the two layers as a result of sprinkler operation. An algorithm for such predictions is presented in a manner that is suitable for general use in two-layer zone-type compartment fire models.

The model is exercised in example calculations which simulate the interaction between the spray of a real sprinkler device and both fire and non-fire environments. The calculations reveal an important generic interaction phenomenon, namely, an abrupt and large change in the growth rate of an upper layer that would accompany an increase in upper layer thickness beyond a critical thickness (for a given upper layer temperature) or an increase in upper layer temperature beyond a critical temperature (for a given upper layer thickness). Exceeding critical values would lead to very large rate of growth of upper layer thickness, a growth that could lead to rapid and complete smoke filling of even the largest compartments of fire origin.

Keywords: building fires; compartment fires; computer models; fire models; mathematical models; vents; sprinklers; sprinkler response; zone models. 


\section{INTRODUCTION}

The overall objective of this work, which was sponsored by the American Architectural Manufacturers Association (AAMA) Research Foundation, was to develop a model to predict the interaction of sprinklers and compartment-firegenerated smoke layers, and to include the effect in an enhanced version of the compartment fire model computer code LAVENT (Link Actuated Vents). The resulting new computer code would be capable of simulating the combined effects of sprinklers and ceiling vents on time-dependent compartment fire environments. The present work is a report of the sprinkler/smoke-layerinteraction part of the problem.

Consider a compartment fire. Assume a two-layer-type description of the firegenerated environment, where the thickness of the layers, i.e., the elevation of the layers' interface, and the assumed-uniform layer properties are known. This paper develops a mathematical model for simulating the interaction of an isolated operating sprinkler and the two-layer environment.

\section{Qualitative Description of the Spray/Layer Interactions}

Depicted in Figure 1 are generic interactions between two-layer fire-generated environments and an operating sprinkler. In Figures $l a$ and $1 b$, the upper elevated-temperature layer submerges the sprinkler nozzle, whereas in Figure 1c, the layer interface is at or above the elevation of sprinkler deployment.

In the Figure $1 \mathrm{a}$ and $1 \mathrm{~b}$ scenarios, the sprinkler spray entrains, drives downward (by aerodynamic drag on the spray drops), humidifies, and cools (by drop evaporation) gases from the high temperature upper layer. A jet of downward-moving gases is formed. Following experimental observations of isolated sprinklers operating in an ambient environment [1] ${ }^{1}$, the downward jet is assumed to be confined to a fixed and specified spray zone of influence, a spray cone envelope.

The jet gases penetrate and emerge from the upper-layer/lower-layer interface as a downward-moving jet of gases. This jet is typically upward-buoyant in the lower layer because of the fact that below the interface the jet gases are usually warmer and less dense than the relatively cool lower layer environment. It is also possible for the penetrating jet to be cooler and more dense than the lower layer environment.

Once in the lower layer, upward buoyant forces on the jet gases would act in a manner as to reduce their downward velocity. Also, downward drag forces and spray evaporation and cooling continue as in the upper layer, albeit with reduced intensity.

In the analysis to be described, it was convenient to divide the lower layer gas jet flows into three major categories depicted in Figures $1 \mathrm{a}$, $1 \mathrm{~b}$, and $1 \mathrm{c}$. These categories involve a total of six different flow conditions identified as ICOND 1 , ICOND $2, \ldots$. ICOND 6 , respectively. As noted, the Figure 1c

\footnotetext{
${ }^{1}$ Numbers in brackets refer to the list of REFERENCES at the end of this paper.
} 
scenario involves the flow condition designated as ICOND 1. The defining features of each of these flow conditions will be described below.

The Sprinkler-Spray/Lower-Layer Interaction of Figure la. Consider the jet gases as they penetrate the layer interface. The sprinkler-spray/lower-layer interaction of the Figure la involves scenarios where: 1 ) there is an upward buoyancy body force on the jet gases immediately below the interface which is strong enough to overcome the downward spray drag force (i.e., the net force on the gases is upward); and 2) the net upward force is strong enough to lead to a jet mass flow which decreases with decreasing elevation (i.e., instead of entrainment from the lower layer environment into the spray cone envelope, immediately below the interface there will be lateral outflow of gases from the spray cone. Define $e^{2}$ as the mass flow rate of all gas entrained into the spray cone between the sprinkler nozzle elevation and an elevation of interest. Then the Figure la scenarios involve cases where $\mathrm{d} \dot{M} / \mathrm{dx} \leq 0$ immediately below the layer interface. As a result, the downward velocity of the jet gases will decrease with decreasing elevation. The velocity may go to zero above the floor at a jet-penetration depth, $\delta_{\mathrm{p}}=\mathrm{x}_{\delta}-\mathrm{x}_{\mathrm{INT}}$, as in shown in the figure (also depicted as ICOND 4 in Figure 2), or the jet may maintain its downward motion until it actually impinges on the floor (depicted as ICOND 3 in Figure 2). Note that within the zone of the spray envelope, evaporation and cooling of jet gases takes place even as they decelerate.

From the layer interface to the elevation of jet penetration, jet gases flow laterally outward from the spray cone axis. The buoyant forces acting on the jet gases as they leave the spray envelope drive them upward, back toward the upper-layer/lower-layer interface. The now-upward-moving plume-like flow, which surrounds the downward-penetrating jet, entrains the relatively cool lower-layer gases. The original, downward-penetrating jet gases, the entrained lower-layer gases, and all the water that was evaporated in the spray cone from the spray drops are assumed to be deposited finally into and mixed with the upper-layer.

Suppose, as depicted in Figure la and in the top of Figure 2, that jet velocity does go to zero above the floor elevation, i.e., ICOND 4. Then, at the penetration-depth elevation the drops of the spray cone emerge from below the upward-buoyant jet. With their remaining downward momentum and with the now-enlarged spray cone cross-sectional area, the drops would initiate a new spray cone gas jet by entrainment from the far-field lower-layer environment. This new jet eventually impinges on the floor. The new jet is analogous to the original jet initiated at the elevation of the sprinkle nozzle. The phenomena associated with the new jet would also be completely analogous to the phenomena described below in association with the Figure lc scenario.

The Sprinkler-Spray/Lower-Layer Interaction of Figure 1b. The sprinklerspray/lower-layer interaction of the Figure $1 \mathrm{~b}$ involves scenarios where immediately below the interface the mass flow of the penetrating jet is increasing with decreasing elevation, i.e., $\mathrm{d} \dot{M} / \mathrm{dx}>0$, even though upward buoyancy may lead to a net upward force on the jet gases. Also, in some nonzero interval below the interface the $\mathrm{d} \dot{\mathrm{M}} / \mathrm{dx}>0$ condition persists as in the

${ }^{2} \mathrm{~A}$ list of NOMENCLATURE is included at the end of this paper. 
upper layer. This is an interval of entrainment into the spray cone of relatively low-temperature lower layer gases.

The generic Figure-lb scenario includes those cases where the lower layer temperature is greater than the temperature of the penetrating jet. In such cases, the buoyancy force on the jet in the lower layer is initially downward, enhancing the downward-directed drag force and remains so until the jet reaches the floor; the jet dynamics in the lower layer are completely analogous to the original flow in the upper layer. The situation involves a flow conditions designated as ICOND 6 and depicted in Figure 3. In general, the distinguishing feature of the ICOND 6 scenario is that $\mathrm{dM} / \mathrm{dx}>0$ throughout the entire depth of the lower layer.

Consider cases in the present category of flow where the jet gases are upward buoyant as they penetrate the interface. These cases are designated as ICOND 2 or 5 and are depicted in Figure 3. It is possible that below the interface $\mathrm{d} \dot{\mathrm{M}} / \mathrm{dx}$ decreases with decreasing elevation and goes to zero at some elevation above the floor. At still lower elevations, the jet velocity would then be reduced with further decreases in elevation. As can be seen in Figure 3 , ICOND 5 is distinguished by the fact that the $\mathrm{d} \dot{\mathrm{M}} / \mathrm{dx}=0$ condition occurs and the velocity actually goes to zero at an elevation above the floor. Flow conditions where: 1) $\mathrm{dM} / \mathrm{dx}=0$ at some elevation, but where the velocity does not go to zero above the floor; or 2) where there is no elevation where $\mathrm{dM} / \mathrm{dx}$ $=0$, are both included in ICOND 2. The former of these two flow conditions are depicted in the ICOND 2 sketch of Figure 3.

Note that in the Figure 3 depiction of ICOND 5 scenarios, spray drops emerge from the elevation of zero velocity and initiate a new downward-directed jet of gases entrained from the lower-layer environment. This is completely analogous to the previously discussed new lower layer jet of the ICOND 4 flow condition.

Eventually the jet gases impinge on the floor. It is assumed that they are then all deposited in and mixed with the rest of the lower layer. Thus, for the scenarios of Figures $1 \mathrm{~b}$ and 3 , whatever the conditions of the jet development in the lower layer, the flow entrained into the spray cone in the elevation interval immediately below the interface is assumed to "shield" the upper layer from the potential entry from the lower layer of any possible upward-buoyant gases driven from the spray cone at lower elevations.

Note that throughout the entire depth of the lower layer an understanding of the dynamics of the gases in the spray cone is required in order to be able to predict the cooling and humidification that takes place there. Thus, along with an estimate of the flow of spray cone gases penetrating the interface and being deposited in the lower layer it is also necessary to estimate the amount of enthalpy and water vapor added to the gases in the lower layer spray cone envelope, since these are also deposited in the lower layer.

The Sprinkler-Spray/Lower-Layer Interaction of Figure 1c. Figure lc depicts the ICOND 6 flow condition. Here the sprinkler is below or at the layer interface. The upper layer is assumed to be unaffected by sprinkler operation. The dynamics of the spray-induced jet of gases in the lower layer is completely analogous to the spray/upper-layer interaction of a Figure la scenario, where the upper layer fills the compartment. In this Figure-lc 
scenario it is again important to predict the net cooling and humidification of jet gases which are deposited into and mixed with the lower layer.

\section{The Objective}

The goal of the work presented here is to develop a mathematical model which can be used in two-layer zone-type compartment fire models to simulate the interaction of sprinklers and two-layer fire environments under arbitrary Figure 1 conditions. The specific objective is to develop a means of predicting the rates of flow of mass, enthalpy, products of combustion, and evaporated water to each of the two layers as a result of sprinkler operation.

\section{Specifying the Two-Layer Fire Environment}

Refer to Figure 1. The upper and lower layers are assumed to have specified densities and absolute temperatures, $\rho_{\mathrm{U}}, \rho_{\mathrm{L}}$ and $\mathrm{T}_{\mathrm{U}}, \mathrm{T}_{\mathrm{L}}$, respectively, where $\mathrm{T}_{\mathrm{U}}$ $>\mathrm{T}_{\mathrm{L}}, \rho_{\mathrm{U}}<\rho_{\mathrm{L}}$, and specified mass fractions of water vapor [ $\left(\mathrm{kg}\right.$ of $\left.\mathrm{H}_{2} 0\right) /(\mathrm{kg}$ gas layer)], $\mathrm{C}_{\mathrm{H} 2 \mathrm{O}, \mathrm{U}}, \mathrm{C}_{\mathrm{H} 2 \mathrm{O}, \mathrm{L}}$ and other products of combustion [( $\mathrm{kg}$ of product $\mathrm{k}) /(\mathrm{kg}$ gas layer $)\}, c_{k, U}, c_{k, L}$ which are taken account of in the simulation (here, the water is both a product of combustion and a product of evaporation from the sprinkler spray drops).

When implementing the equations in a compartment fire model, the specification of layer product concentrations, including the water concentration, would be required only when such concentrations are actually being predicted in the overall fire model simulation. Thus, the present sprinkler/layer interaction model does not depend on specification of the instantaneous upper- and lowerlayer concentration of water. This is in spite of the fact that (1) the model predicts, among other parameters, the rate of water evaporation and cooling from the sprinkler spray drops and that (2) such evaporation is generally a function of the humidity of the gases entrained into the zone of influence of the water spray. The reason that specification of water concentrations is not required is that the models used here for predicting the rate of evaporative cooling [2] and the aerodynamic drag [3] of evaporating water droplets are based on the assumption that the relative humidity of the gases in the water spray envelope is negligible. This is expected to be a reasonable assumption since most of the evaporative cooling is expected to occur at gas temperatures at least several tens of degrees $\mathrm{K}$ above ambient conditions. At such temperatures, high relative humidity conditions would require the gases to have unrealistically high mass fractions of water.

\section{FORMULATION OF THE PROBLEM FOR THE FLOWS IN THE SPRAY CONE ENVELOPE}

\section{Fragmentation of the Nozzle Flow - The Spray Cone Envelope}

Refer to Figure 1. Relative to some datum elevation, the elevation of the interface separating the upper and lower layers is $\mathrm{y}_{\text {LAYER }}$. The sprinkler nozzle outlet is located at elevation, $y_{S P R I N K}$, which is assumed to be at or below the elevation of the ceiling, $y_{C E I L}$, but above that of the floor, $\mathrm{y}_{\mathrm{FLOOR}}$. At an elevation $\mathrm{y}_{\text {SPRAY }}$, relatively close to $\mathrm{y}_{\mathrm{SPRINK}}$, the breakup into drops of the outlet stream of the nozzle is assumed to be complete, e.g., by 
virtue of being fragmented by impingement with a sprinkler striker plate, or by break-up due to fluid-dynamic instabilities of the stream. At elevation $y_{S P R A Y}$ and below, the spray is assumed to be well-simulated as having a conelike volume of influence, where the cone has an angle of $\theta$, a specified characteristic of the sprinkler device. (Reference [1] considers devices with spray cone angles from $30^{\circ}$ to $120^{\circ}$.) The (virtual) apex of the cone is designated as being a distance $|x|=x_{W}$ above $y_{S P R A Y}$, where $x$ is designated as the axial distance measured downward from the cone apex along the spray-cone axis. Corresponding to $x$ and $x_{W}$ are the spray-cone diameters $D$ and $D_{W}$, respectively, i.e.,

$$
\mathrm{D}=2 \mathrm{x} \tan (\theta / 2) ; \mathrm{D}_{\mathrm{W}}=2 \mathrm{x}_{\mathrm{W}} \tan (\theta / 2)
$$

The sprinkler nozzle diameter and its volumetric water discharge rate are designated as $D_{N}$ and $\dot{V}_{N}$, respectively. Also, the downward velocity of the flow in the nozzle is designated as $u_{N}$

$$
\mathrm{u}_{\mathrm{N}}=\dot{\mathrm{V}}_{\mathrm{N}} /\left(\pi \mathrm{D}_{\mathrm{N}}^{2} / 4\right)
$$

It is assumed that $D_{N}$ and either $u_{N}$ or $\dot{V}_{N}$ are specified. In general, fragmentation of the nozzle stream between elevations $\mathrm{y}_{S P R I N K}$ and $\mathrm{y}_{S P R A Y}$ is accompanied by a loss of its downward momentum, this loss being a characteristic of the sprinkler design. Designate $\mathrm{C}_{\mathrm{M}}$ as the ratio of the initial downward momentum flow rate of the water spray at $\mathrm{y}_{S P R A Y}$ to the momentum flow rate of the water stream as it leaves the sprinkler nozzle at $\mathrm{y}_{S P_{R I N K}} . \mathrm{C}_{M}$ is assumed to be a specified characteristic of the particular sprinkler device being simulated. A representative $C_{M}$ value for standard sprinklers is 0.4 [1].

The drops of the water spray are modeled as being uniform spheres with diameters equal to the mean-volume diameter, $d$. Measurements indicate the following correlation for air-water spray/sprinkler systems

$$
\mathrm{d}=r\left(\mathrm{D}_{\mathrm{N}} / \mathrm{u}_{\mathrm{N}}\right)^{2 / 3}
$$

where $r$ is a specified drop-size parameter which is generally dependent on the relative geometry of the spray device. Typical standard sprinklers have $r$ values of $0.084 \mathrm{~m} / \mathrm{s}^{2 / 3}[1]$.

\section{Drag Forces Between the Drops and the Jet Gases}

The downward velocity of the drops leads to a momentum transfer due to aerodynamic drag-force interactions between the drops and the gas. This results in a downward flow of the gas within the spray cone and relatively low pressure there. The low pressures drive an entrainment of gases toward the spray cone axis from the relatively quiescent and higher-pressure farfield environment. With increasing $x$, conservation of vertical momentum along the spray cone axis requires increases in downward velocity of the gas 
(acceleration) at the expense of decreases in the downward velocity of the drops (deceleration). The result is the formation of a downward jet of upper layer gas in the spray cone envelope.

In the spray cone, differences in local velocity and temperature of gas and drops lead to evaporative cooling. The drag force on a single water drop evaporating in air in the Reynolds number-range of interest, $10<\operatorname{Re}<1000$, can be approximated by [1]

$$
\left|F_{d}\right|=(1 / 2) \rho_{s} u_{R E L}^{2} C_{D}\left(\pi d^{2} / 4\right)
$$

where

$$
C_{D}=B / R^{1 / 2}
$$

and where $u_{R E L}$ is the magnitude of the difference in velocity between the drops and the free-stream gas, B is a constant, taken to be 12.6, and [3]

$$
\operatorname{Re}=u_{\mathrm{REL}} \mathrm{d} \rho_{\mathrm{s}} / \mu_{1 / 3}
$$

In Eq. (6), $\rho_{\mathrm{s}}$ is the local density of the free-stream gas and $\mu_{1 / 3}$ is the dynamic viscosity of the gas evaluated at a temperature based on "the 1/3 rule." In particular, the dynamic viscosity of air is taken to be $\mu=\mu(\mathrm{T})$ and

$$
\begin{aligned}
& \mu_{1 / 3}=\mu\left(\mathrm{T}_{1 / 3}\right) \\
& \mathrm{T}_{1 / 3} \equiv \mathrm{T}_{\mathrm{p}}+\left(\mathrm{T}_{\mathrm{s}}-\mathrm{T}_{\mathrm{p}}\right) / 3
\end{aligned}
$$

where $T_{p}$ and $T_{s}$ are the drop surface temperature and local air temperature, respectively. Note that experimental results of [3] indicate that for evaporating water drops in the Re range of interest, Eq. (5), with an Eq.-(6) calculation of $\operatorname{Re}$ based on $\mu_{\mathrm{s}}$ rather than $\mu_{1 / 3}$, will typically lead to a predicted value for $C_{D}$ that is a several tens of percent greater than the true value. It was this latter value of $R e$ that was used in [1] and [4] to compute $\mathrm{F}_{\mathrm{d}}$ in $\mathrm{Eq} .(4)$.

Under steady state conditions the evaporation process would keep the drop surface temperature at the wet bulb temperature corresponding to $T_{s}[3]$. This is also assumed to hold in the quasi-steady processes being modeled here. Reference [4] provides the following curve fit to reference-[3] $T_{p}\left(T_{s}\right)$ data for water for the range $373 \mathrm{~K} \leq \mathrm{T}_{\mathrm{s}} \leq 1273 \mathrm{~K}$

$$
\mathrm{T}_{\mathrm{p}} / \mathrm{K}=266\left[1+3.23(10)^{-4} \mathrm{~T}_{\mathrm{s}} / \mathrm{K}\right]
$$

For air, it is now assumed, as in [4], that 


$$
\begin{aligned}
& \mu=\rho \nu \propto(\mathrm{T} / \mathrm{K})^{0.7} \\
& \rho \mathrm{T}=\text { constant }
\end{aligned}
$$

where $\nu$ is the kinematic viscosity, and that at the reference temperature, $\mathrm{T}_{\mathrm{REF}}$,

$$
\begin{aligned}
& \rho_{\mathrm{REF}} \equiv \rho\left(\mathrm{T}=\mathrm{T}_{\mathrm{REF}}=293 \mathrm{~K}\right)=1.2 \mathrm{~kg} / \mathrm{m}^{3} \\
& \nu_{\mathrm{REF}} \equiv \nu\left(\mathrm{T}=\mathrm{T}_{\mathrm{REF}}=293 \mathrm{~K}\right)=1.49\left(10^{-5}\right) \mathrm{m}^{2} / \mathrm{s}
\end{aligned}
$$

Using Eqs. (8)-(10) in Eq. (6) leads to

$$
\begin{aligned}
& \operatorname{Re}=\left(u_{R E L} d / \nu_{R E F}\right) /\left[0.518 T_{s}^{*}\left(T_{s}^{*}+1.55\right)^{0.7}\right] \\
& T_{s}^{*}=T_{s} / T_{R E F}
\end{aligned}
$$

The latter result will be used below in calculating $F_{d}$ from Eqs. (4) and (5).

Heat and Mass Transfer Between the Drops and the Jet Gases

Consider an evaporating water drop in air with the drop surface temperature and local free stream air temperature of $T_{p}$ and $T_{s}$, respectively. Then $\dot{q}_{d}$, the rate of heat transfer to the air from a single drop, is [2]

$$
\dot{\mathrm{q}}_{\mathrm{d}}=-\mathrm{h} \pi \mathrm{d}^{2}\left(\mathrm{~T}_{\mathrm{s}}-\mathrm{T}_{\mathrm{p}}\right)
$$

where $h$ is the heat transfer coefficient. For a condition of non-zero relative motion between the drop and the free stream,

$$
\mathrm{Nu}=\mathrm{hd} / \mathrm{k}=\left[2+0.6 \operatorname{Re}_{\mathrm{M}}^{1 / 2} \operatorname{Pr}^{1 / 3}\right] /\left(1+\mathrm{B}^{\prime}\right)
$$

In the above equation, $k, B^{\prime}, R_{M}$ and $\operatorname{Pr}$ are the thermal conductivity of air, mass transfer number, Reynolds number, and Prantdl number, respectively. The material properties are evaluated at particular characteristic temperatures of the air/liquid flow system specified in [2]. The experiments of [2] were in the range $200<\mathrm{Re}_{\mathrm{M}}<2000$.

Using Eqs. (8)-(10) and a curve fit to $B^{\prime}\left(T_{s}\right)$ data for water presented in [2] (range $373 \mathrm{~K} \leq \mathrm{T}_{\mathrm{s}} \leq 1273 \mathrm{~K}$ ), reference [4] provides the following working version of Eq. (13) for air/water systems 


$$
\begin{aligned}
& \mathrm{h} /\left[\mathrm{kW} /\left(\mathrm{m}^{2} \cdot \mathrm{K}\right)\right]= \\
& \left\{5.16\left(10^{-5}\right)+4.55\left(10^{-3}\right) \mathrm{T}_{\mathrm{s}}^{*-1 / 2}\left(\mathrm{~T}_{\mathrm{s}}^{*}+0.836\right)^{-2 / 5}\left|\mathrm{u}_{\mathrm{p}}-\mathrm{u}_{\mathrm{s}}\right|\left(\mathrm{d} / \mathrm{m}^{3}\right)^{1 / 2} \mathrm{~s}\right\} / \\
& \\
& \left\{\left[1+0.100\left(\mathrm{~T}_{\mathrm{s}}^{*}-0.932\right)^{1.19}\right] \mathrm{T}_{\mathrm{s}}^{*-0.85} \mathrm{~d} / \mathrm{m}\right\}
\end{aligned}
$$

where the specific heat at constant pressure, $C_{p}$, and the thermal conductivity for air were taken to be constant at their $T_{R E F}$ values. Note that it is impossible for $\mathrm{T}_{\mathrm{s}}^{*}-0.932=0$ in the denominator of $\mathrm{Eq}$. (14) since this corresponds to $\mathrm{T}_{\mathrm{s}}=273 \mathrm{~K}$, which is outside the equation's intended range of use.

It will be assumed here that throughout the spray cone envelope the drop temperatures are always uniform at the local value of $\mathrm{T}_{\mathrm{p}}$. ( $\mathrm{T}_{\mathrm{p}}$ varies between $306 \mathrm{~K}$ and $368 \mathrm{~K}$ for $T_{s}$ in the range $373 \mathrm{~K} \leq T_{s} \leq 1273 \mathrm{~K} \mathrm{[3]}{ }^{\mathrm{P}}$ ) Also, when using Eqs. (12) and (14) it is assumed that the rate of energy transfer to the drop required to maintain its changing $\mathrm{T}_{\mathrm{p}}$ value is negligible compared to the rate of heat transfer of Eq. (12). In other words, all heat transfer to the drop from the air is assumed to be used in the evaporation process. Finally, once the drops are formed near the sprinkler nozzle, the total mass evaporated during their motion from $\mathrm{y}_{S P R A Y}$ to $\mathrm{y}_{F L O O R}$ is assumed to be negligible compared to their original mass.

In view of the above, $\dot{m}_{d}$, the rate of mass transfer of water vapor from a drop to the jet gases, i.e., the rate of evaporation of a drop, is obtained from Eq. (12) to be

$$
\dot{\mathrm{m}}_{\mathrm{d}}=-\dot{\mathrm{q}}_{\mathrm{d}} / \mathrm{L}_{\mathrm{w}}
$$

where $L_{W}$ is the latent heat of vaporization of water taken to be $2.26\left(10^{3}\right) \mathrm{kJ} / \mathrm{kg}[4]$.

\section{Problem Variables and Parameters}

The gas temperature is modeled as being uniform across a section of the spray cone, i.e., $\mathrm{T}_{\mathrm{s}}=\mathrm{T}_{\mathrm{s}}(\mathrm{x})$. The downward drop and gas velocities in the spray cone are also modeled as depending only on $x$. These are designated as $u_{p}(x)$ and $u_{s}(x)$, respectively. The values of $u_{p}, u_{s}$, and $T_{s}$ at $x_{w}$ are denoted by $u_{p 0}, u_{s 0}$, and $T_{s 0}$

$$
u_{p 0} \equiv u_{p}\left(x=x_{W}\right) ; \quad u_{s 0} \equiv u_{s}\left(x=x_{W}\right) ; T_{s 0} \equiv T_{s}\left(x=x_{W}\right)
$$

It is assumed that the initial value for $u_{s}$ is zero, i.e., the downward air velocity at the elevation $\mathrm{Y}_{S P R A Y}$ is zero and any air entrainment between the elevations $\mathrm{y}_{\text {SPRINK }}$ and $\mathrm{y}_{\text {SPRAY }}$ is neglected. It is noteworthy that in [1], for sprays interacting with an ambient environment, calculated downstream values 
of $u_{s}$ in the absence of evaporative cooling effects were shown not to be particularly sensitive to its initial value.

The initial value for $T_{s}$ is taken to be $T_{L A Y E R}$, the local layer temperature, i.e., either $\mathrm{T}_{\mathrm{U}}$ or $\mathrm{T}_{\mathrm{L}}$. Thus

$$
\begin{aligned}
& \mathrm{T}_{\text {s } 0}=\mathrm{T}_{\mathrm{LAYER}} \\
& \mathrm{u}_{\mathrm{s} 0}=0
\end{aligned}
$$

Conservation of mass requires identical values of mass flow rate of the water at the nozzle exit and at $x=x_{W}$. It follows from the definition of $C_{M}$ that

$$
u_{p 0}=C_{M} u_{N}
$$

Also, $D_{W}$ is taken as [1]

$$
D_{W}=D_{N} / C_{M}{ }^{1 / 2}
$$

Using conservation of mass, it can be shown that Eq. (19) is consistent with the picture of a solid water jet spreading and decelerating from the nozzle exit to the position of its fragmentation at $y_{S P R A Y}$.

Along with $\mathrm{T}_{\mathrm{s}}^{*}$ of Eq. (11), dimensionless values of the other variables are defined by

$$
\begin{aligned}
& u_{p}^{*}=u_{p} / u_{p 0} ; u_{s}^{*}=u_{s} / u_{p 0} ; \\
& T_{L A Y E R}^{*}=T_{L A Y E R} / T_{R E F} ; \\
& x^{*}=x / D_{W}=x_{M} 1 / 2 / D_{N}
\end{aligned}
$$

\section{Conservation Equations for the Spray Envelope}

Conservation of Mass for the Drops - the Drop Number Density. With specified values of $\dot{V}_{N}$, and $d$, and for an arbitrary $x$, conservation of mass for the water in the spray cone is invoked in terms of a determination of the number density of drops in the cone. Define

$$
\mathrm{N}=\text { number of drops per unit volume }
$$

Equating the volume flow rate of drops at an arbitrary $x$ to the volume flow rate from the nozzle leads to the result 


$$
\mathrm{N}=(3 / 2) \mathrm{u}_{\mathrm{N}}^{2} /\left[\pi \mathrm{r}^{3} \mathrm{D}_{\mathrm{N}}^{2} \tan ^{2}(\theta / 2) \mathrm{u}_{\mathrm{p}}^{*} \mathrm{x}^{* 2}\right]
$$

\section{Conservation of Mass for the Gas. Define}

$$
\begin{aligned}
& \dot{\mathrm{M}} \equiv \text { mass flow rate of layer gases entrained into the spray } \\
& \text { cone from } x_{\mathrm{W}} \text { to } \mathrm{x}
\end{aligned}
$$

Since there is no mass flow of gas at $x_{W}$ and since the contribution of evaporating water to the mass flow rate of gas in the spray cone is negligible it follows that

$$
\begin{aligned}
\dot{\mathrm{M}} & =\text { mass flow rate of gases in the spray cone at } \mathrm{x} \\
& =\rho_{\mathrm{s}} \mathrm{u}_{\mathrm{s}} \mathrm{A}_{\mathrm{SPRAY}}
\end{aligned}
$$

where $A_{S P R A Y}$, the cross-section area of the spray, is given by

$$
A_{\text {SPRAY }}=\pi D^{2} / 4
$$

In the analysis to follow it will be useful to calculate $d \dot{M} / d x$. Using Eq. (24), this would be obtained from

$$
d \dot{M} / d x=\rho_{s} A_{S P R A Y} d u_{s} / d x+\rho_{s} u_{s} d A_{S P R A Y} / d x+\sigma u_{s} A_{S P R A Y} d \rho_{s} / d x
$$

In Eq. (26), $\sigma$ is used to mark the last term which would be neglected in an analysis that involved the Bousinesque approximation, i.e., changes in gas density and temperature are taken account of only as they affect body forces terms (buoyancy) in the momentum equation. Thus

$$
\sigma=\left\{\begin{array}{l}
0 \text { with the Bousinesque approximation } \\
1 \text { without the Bousinesque approximation }
\end{array}\right.
$$

The following dimensionless variable for $\dot{M}$ is introduced

$$
\begin{aligned}
\dot{M}^{*} & \equiv \dot{M} /\left[4 \rho_{R E F} \dot{V}_{\mathrm{N}} \tan ^{2}(\theta / 2)\right] \\
& =[\dot{M} /(\mathrm{kg} / \mathrm{s})] /\left[(1.2 \pi)\left(\mathrm{u}_{\mathrm{N}} \mathrm{s} / \mathrm{m}\right)\left(\mathrm{D}_{\mathrm{N}} / \mathrm{m}\right)^{2} \tan ^{2}(\theta / 2)\right] \\
& =[\dot{\mathrm{M}} /(\mathrm{kg} / \mathrm{s})] /\left[4(1.2)\left(\dot{\mathrm{V}}_{\mathrm{N}} \mathrm{s} / \mathrm{m}^{3}\right) \tan ^{2}(\theta / 2)\right]
\end{aligned}
$$


Eqs. (24)-(26) and (28) lead to

$$
\begin{aligned}
& \dot{\mathrm{M}}^{*}=\mathrm{u}_{\mathrm{s}}^{*} \mathrm{x}^{*} 2 / \mathrm{T}_{\mathrm{s}}^{*} \\
& \mathrm{~d}^{*} / \mathrm{dx} \mathrm{M}^{*}=\left(\mathrm{x}^{*} 2 / \mathrm{T}_{\mathrm{s}}^{*}\right)\left[\mathrm{du}_{\mathrm{s}}^{*} / \mathrm{d} \mathrm{x}^{*}+2 \mathrm{u}_{\mathrm{s}}^{*} / \mathrm{x}^{*}-\sigma\left(\mathrm{u}_{\mathrm{s}}^{*} / \mathrm{T}_{\mathrm{s}}^{*}\right) \mathrm{dT}_{\mathrm{s}}^{*} / \mathrm{dx^{* }}\right]
\end{aligned}
$$

Note that once the $\mathrm{u}_{\mathrm{s}}^{*}$ and $\mathrm{T}_{\mathrm{s}}^{*}$ variables are determined, $\dot{\mathrm{M}}^{*}$ can be determined directly from Eq. (29).

Conservation of Momentum for the Drops. Conservation of momentum for a water drop leads to

$$
\mathrm{du}_{\mathrm{p}}^{*} / \mathrm{dx} \mathrm{x}^{*}=\omega_{1} / \mathrm{u}_{\mathrm{p}}^{*}-\omega_{2}\left(\mathrm{~T}_{\mathrm{s}}^{*}+1.55\right)^{0.35}\left(\mathrm{u}_{\mathrm{p}}^{*}-\mathrm{u}_{\mathrm{s}}^{*}\right)^{3 / 2} /\left(\mathrm{T}_{\mathrm{s}}^{* 1 / 2} \mathrm{u}_{\mathrm{p}}^{*}\right)
$$

where

$$
\begin{aligned}
\omega_{1} & =g D_{N} /\left(u_{N}^{2} C_{M}^{5 / 2}\right) \\
& =9.8\left(D_{N} / m\right) /\left[\left(u_{N} s / m\right)^{2} C_{M}^{5 / 2}\right] \\
& =9.8(\pi / 4)^{2}\left(D_{N} / m\right)^{5} /\left[\left(\dot{V}_{\mathrm{N}} s / m^{3}\right)^{2} C_{M}^{5 / 2}\right] \\
\omega_{2} & =0.540 B\left(\nu_{R E F} u_{N} / \mathrm{r}^{3}\right)^{1 / 2}\left(\rho_{R E F} / \rho_{W}\right) / C_{M} \\
& =3.15\left(10^{-5}\right)\left(u_{N} s / m\right)^{1 / 2} /\left[\left(\mathrm{rs}^{2 / 3} / \mathrm{m}\right)^{3 / 2} C_{M}\right] \\
& =3.15\left(10^{-5}\right)\left[(4 / \pi)\left(\dot{V}_{N} s / m^{3}\right)\right]^{1 / 2} /\left[\left(D_{N} / m\right)\left(r s^{2 / 3} / m\right)^{3 / 2} C_{M}\right]
\end{aligned}
$$

and where $\rho_{W}$ is the density of water, taken to be $1.0\left(10^{3}\right) \mathrm{kg} / \mathrm{m}^{3}$. On the right hand side of Eq. (31), the first and second terms represent the forces on a drop as a result of gravity and aerodynamic drag, respectively. The drag force was determined from Eqs. (4), (5), and (11). Also, g is the acceleration due to gravity, $9.8 \mathrm{~m} / \mathrm{s}^{2}$.

Eq. (31) corresponds to Eq. (12) of [1] or Eq. (1) of [4], except for differences in the evaluation of Re discussed below Eq. (7). In [4], which deals with the two-layer fire environment, Eq. (31) was only used in the upper layer. Here, Eq. (31) and all conservation-derived equations, presented below, will be used to simulate the dynamics in the spray cone in both the upper and lower layers for all scenarios of Figures 1-3. 
Conservation of Momentum for the Gas. Conservation of momentum for the gas in the spray cone leads to

$$
\begin{aligned}
\mathrm{du}_{\mathrm{s}}^{*} / \mathrm{dx} \mathrm{x}^{*}=-\mathrm{u}_{\mathrm{s}}^{*} / \mathrm{x}^{*}+\omega_{3} \mathrm{~T}_{\mathrm{s}}^{* 1 / 2}\left(\mathrm{~T}_{\mathrm{s}}^{*}+1.55\right)^{0.35}\left(\mathrm{u}_{\mathrm{p}}^{*}-\mathrm{u}_{\mathrm{s}}^{*}\right)^{3 / 2} /\left(\mathrm{u}_{\mathrm{p}}^{*} \mathrm{u}_{\mathrm{s}}^{*} \mathrm{x}^{* 2}\right)+ \\
\omega_{4}\left(1-\mathrm{T}_{\mathrm{s}}^{*} / \mathrm{T}_{\mathrm{LAYER}}^{*}\right) / \mathrm{u}_{\mathrm{s}}^{*}+\sigma\left[\mathrm{u}_{\mathrm{s}}^{*} /\left(2 \mathrm{~T}_{\mathrm{s}}^{*}\right)\right] \mathrm{dT}_{\mathrm{s}}^{*} / \mathrm{dx}^{*}
\end{aligned}
$$

where

$$
\begin{aligned}
& \omega_{3}^{\prime}=\omega_{2}\left(\rho_{\mathrm{W}} / \rho_{\mathrm{REF}}\right) /\left[8 \tan ^{2}(\theta / 2)\right]=1.04\left(10^{2}\right) \omega_{2} / \tan ^{2}(\theta / 2) \\
& \omega_{4}=\mathrm{gD}_{\mathrm{N}} /\left(\mathrm{u}_{\mathrm{N}}{ }^{2} \mathrm{C}_{\mathrm{M}}{ }^{3 / 2}\right)=\mathrm{C}_{\mathrm{M}} \omega_{1}
\end{aligned}
$$

On the right hand side of Eq. (34), the second and third terms represent the forces on the gas as a result of aerodynamic drag and gravity (buoyancy), respectively. The drag force term is equivalent to and in the opposite direction of the corresponding single-drop drag force term of Eq. (31). The drag force per unit volume on the gas, used in the derivation of Eq. (34), was found by determining $\mathrm{NF}_{\mathrm{d}}$ from Eqs. (4) and (22).

Eq. (34), with $\sigma=0$ and without the buoyancy term, corresponds to Eq. (2) of [4], except for differences in the evaluation of $R e$, as discussed below Eq. (7).

Conservation of Energy for the Gas. Conservation of energy for the gas in the spray cone leads to

$$
\begin{aligned}
\mathrm{dT}_{\mathrm{s}}^{*} / \mathrm{dx} \mathrm{x}^{*}=\left(\mathrm{T}_{\mathrm{s}}^{*} / \mathrm{u}_{\mathrm{s}}^{*}\right)\left[\mathrm{f}\left(\dot{\mathrm{M}}^{*}\right)\left(\mathrm{du} u_{\mathrm{s}}^{*} / \mathrm{dx^{* }}+2 \mathrm{u}_{\mathrm{s}}^{*} / \mathrm{x}^{*}\right)-\right. \\
\left.\omega_{5}\left(\mathrm{~T}_{\mathrm{s}}^{*}-0.993\right) \mathrm{h}^{*}\left(\mathrm{~T}_{\mathrm{s}}^{*}, \mathrm{u}_{\mathrm{s}}^{*}, u_{\mathrm{p}}^{*}\right) /\left(\mathrm{u}_{\mathrm{p}}^{*} \mathrm{x}^{*}\right)\right] /\left[1+\sigma f\left(\dot{\mathrm{M}}^{*}\right)\right]
\end{aligned}
$$

where

$$
\begin{aligned}
& f\left(\dot{M}^{*}\right)=\left\{\begin{array}{l}
0 \text { if } d_{M^{*}} / d x^{*} \leq 0 \\
\left(T_{L A Y E R}^{*} / T_{s}^{*}-1\right) \text { if } d_{M^{*}}^{*} / d x^{*}>0
\end{array}\right. \\
& \omega_{5}=1.14\left[\left(D_{N} / m\right) /\left(u_{N} \mathrm{~s} / \mathrm{m}\right)\right]^{1 / 3} /\left[\left(\mathrm{rs}^{2 / 3} / \mathrm{m}\right) C_{M} \tan ^{2}(\theta / 2)\right] \\
& =1.14\left(D_{N} / \mathrm{m}\right) /\left[(4 / \pi)^{1 / 3}\left(\dot{V}_{N} \mathrm{~s} / \mathrm{m}^{3}\right)^{1 / 3}\left(\mathrm{rs}^{2 / 3} / \mathrm{m}\right) C_{M} \tan ^{2}(\theta / 2)\right]
\end{aligned}
$$




$$
\begin{aligned}
& \mathrm{h}^{*}\left(\mathrm{~T}_{\mathrm{s}}^{*}, \mathrm{u}_{\mathrm{s}}^{*}, \mathrm{u}_{\mathrm{p}}^{*} ; \lambda_{1}, \lambda_{2}\right)= \\
& \quad\left[5.16\left(10^{-5}\right)+4.55\left(10^{-3}\right) \lambda_{1} \mathrm{~T}_{\mathrm{s}}^{*-1 / 2}\left(\mathrm{~T}_{\mathrm{s}}^{*}+0.836\right)^{-2 / 5}\left|\mathrm{u}_{\mathrm{p}}^{*}-\mathrm{u}_{\mathrm{s}}^{*}\right|\right] / \\
& \left.\quad\left[1+0.100\left(\mathrm{~T}_{\mathrm{s}}^{*}-0.932\right)^{1.19}\right] \lambda_{2}\right]^{*} \\
& \lambda_{1}=\left(\mathrm{u}_{\mathrm{N}} \mathrm{s} / \mathrm{m}\right)^{2 / 3}\left(\mathrm{D}_{\mathrm{N}} / \mathrm{m}\right)^{1 / 3}\left(\mathrm{rs}^{2 / 3} / \mathrm{m}\right)^{1 / 2} \\
& =(4 / \pi)^{2 / 3}\left(\dot{\mathrm{V}}_{\mathrm{N}} \mathrm{s} / \mathrm{m}^{3}\right)^{2 / 3}\left(\mathrm{rs}^{2 / 3} / \mathrm{m}\right)^{1 / 2} /\left(\mathrm{D}_{\mathrm{N}} / \mathrm{m}\right) \\
& \lambda_{2}=\left(\mathrm{D}_{\mathrm{N}} / \mathrm{m}\right)^{2 / 3}\left(\mathrm{rs}^{2 / 3} / \mathrm{m}\right) /\left(\mathrm{u}_{\mathrm{N}} \mathrm{s} / \mathrm{m}\right)^{2 / 3} \\
& =\left(\mathrm{D}_{\mathrm{N}} / \mathrm{m}\right)^{2}\left(\mathrm{rs}^{2 / 3} / \mathrm{m}\right) /\left[(4 / \pi)\left(\dot{\mathrm{V}}_{\mathrm{N}} \mathrm{s} / \mathrm{m}^{3}\right)\right]^{2 / 3}
\end{aligned}
$$$$
\left\{\left[1+0.100\left(T_{s}^{*}-0.932\right)^{1.19}\right] \lambda_{2} T_{s}^{*}-0.85\right\}
$$

The heat transfer per unit volume to the gas from the evaporating drops was used in the derivation of Eq. (37). This is reflected in the term with the coefficient $\omega_{5}$. It was found by determining $\mathrm{Nq}_{d}$ from Eqs. (12) and (22).

The two terms on the right side of Eq. (37), with the coefficient $f\left(\dot{M}^{*}\right)$, represent contributions to $\mathrm{dT}_{\mathrm{s}}^{*} / \mathrm{dx}^{*}$ because of air being entrained into the jet gases from the far field at a temperature, $T_{L A Y E R}$, different than $T_{s}$. As seen in Eq. (38), these terms can lead to a non-zero contribution only at $x^{*}$ 's where the entrainment rate is positive, i.e., $\mathrm{d}^{*} / \mathrm{dx}^{*}>0$. At elevations in the jet where there is lateral outflow from the jet, as is the case below the interface in the scenario of, e.g., Figure $1 \mathrm{a}, \mathrm{dM}^{*} / \mathrm{dx}^{*} \leq 0$, and $f\left(\dot{M}^{*}\right)=0$. Thus, Eq. (37) is seen to correctly predict that the terms in question do not directly affect $\mathrm{dT}_{\mathrm{s}}^{*} / \mathrm{dx}^{*}$.

In deriving Eqs. (37)-(42), the value of $\left(\mathrm{T}_{\mathrm{s}}^{*}-\mathrm{T}_{\mathrm{p}}^{*}\right)$, required in the dimensionless version of Eq. (12), was found from Eq. (8) to be

$$
\left(T_{s}^{*}-T_{p}^{*}\right)=0.914\left(T_{s}^{*}-0.993\right)
$$

This explains the appearance of the ( $\left.T_{s}^{*}-0.993\right)$ coefficient in Eq. (37). Finally, the value of $C_{p}$ was required in the determination of $\omega_{5}$. This was taken to be [5]

$$
C_{p}=C_{p}\left(T_{R E F}\right)=1.004 \mathrm{~kJ} /(\mathrm{kg} \cdot \mathrm{K})
$$

The Rate of Heat Transfer and Evaporation from the Drops. From $\mathrm{N}$ of Eq. (22) and $\dot{q}_{d}$ of Eq. (12) it is possible to compute the total rate of heat transfer to the gas from the drops from $x_{w}$ to $x$. Define 
$\dot{Q}_{d} \equiv$ rate of heat transfer from the drops to the gas in the spray cone between $x_{W}$ and $x$

$$
=\int_{\mathrm{X}_{\mathrm{W}}}^{\mathrm{x}} \mathrm{N} \dot{\mathrm{q}}_{\mathrm{d}} \mathrm{A}_{\text {S PRAY }} \mathrm{dx}
$$

The following dimensionless variable for $\dot{Q}_{d}$ is introduced

$$
\begin{aligned}
\dot{\mathrm{Q}}_{\mathrm{d}}^{*} & \equiv\left\{\mathrm{C}_{\mathrm{M}}{ }^{1 / 2} /\left[\pi \mathrm{D}_{\mathrm{N}}^{2} \tan ^{2}(\theta / 2) \rho_{\mathrm{REF}} \mathrm{C}_{\mathrm{p}} \mathrm{T}_{\mathrm{REF}} \mathrm{u}_{\mathrm{n}}\right]\right\} \dot{\mathrm{Q}}_{\mathrm{d}} \\
& =\left\{0.902\left(10^{-3}\right) \mathrm{C}_{\mathrm{M}}{ }^{1 / 2} /\left[\left(\mathrm{D}_{\mathrm{N}} / \mathrm{m}\right)^{2}\left(\mathrm{u}_{\mathrm{N}} \mathrm{s} / \mathrm{m}\right) \tan ^{2}(\theta / 2)\right]\right\}\left[\dot{\mathrm{Q}}_{\mathrm{d}} / \mathrm{kW}\right] \\
& =\left\{0.902\left(10^{-3}\right) \mathrm{C}_{\mathrm{M}}{ }^{1 / 2} /\left[(4 / \pi)\left(\dot{\mathrm{V}}_{\mathrm{N}} \mathrm{s} / \mathrm{m}^{3}\right) \tan ^{2}(\theta / 2)\right]\right\}\left[\dot{\mathrm{Q}}_{\mathrm{d}} / \mathrm{kW}\right]
\end{aligned}
$$

Then from Eq. (45), it can be shown that

$$
\begin{aligned}
& \mathrm{d} \dot{Q}_{\mathrm{d}}^{*} / \mathrm{dx} \mathrm{x}^{*}=-\omega_{5}\left(\mathrm{~T}_{\mathrm{s}}^{*}-0.993\right) \mathrm{h}^{*}\left(\mathrm{~T}_{\mathrm{s}}^{*}, \mathrm{u}_{\mathrm{s}}^{*}, \mathrm{u}_{\mathrm{p}}^{*} ; \lambda_{1}, \lambda_{2}\right) / \mathrm{u}_{\mathrm{p}}^{*} \\
& \dot{\mathrm{Q}}_{\mathrm{d}}^{*}\left(\mathrm{x}^{*}=\mathrm{x}_{\mathrm{W}}^{*}\right)=0
\end{aligned}
$$

where $\omega_{5}$ and $h^{*}$ are given in Eqs. (39)-(42). Note that the right side of Eq. (47) corresponds to the heat transfer term of Eq. (37).

Eqs. (47) and (48) properly indicate that the heat transfer to the gas due to drop evaporation is negative. Define

$$
\begin{aligned}
& \dot{\mathrm{M}}_{\mathrm{d}} \equiv \text { rate of water evaporation from all drops in the spray cone } \\
& \text { between } x_{W} \text { and } x
\end{aligned}
$$

As discussed earlier, all heat transfer to the drops is assumed to lead to their evaporation, where the released water vapor is mixed into and convected along with the rest of the jet gases. Consistent with Eq. (15)

$$
\dot{\mathrm{M}}_{\mathrm{d}}=-\dot{\mathrm{Q}}_{\mathrm{d}} / \mathrm{L}_{\mathrm{W}}
$$

The Generalized Equation Set for $u_{p}^{*}, u_{s}^{*}, T_{s}^{*}, \dot{Q}_{d}^{*}, \dot{M}^{*}$, and $\dot{\mathrm{M}}_{d}$

Eqs. (31), (34), and (37) represent an independent, coupled equation set for $\mathrm{du}_{\mathrm{p}}^{*} / \mathrm{dx}^{*}, \mathrm{du}_{\mathrm{s}}^{*} / \mathrm{dx}^{*}$, and $\mathrm{dT}_{\mathrm{s}}^{*} / \mathrm{dx}^{*}$. In its present form, an explicit representation of this set of equations at an arbitrary $x^{*}$ and under arbitrary conditions appears to depend on a priori knowledge of the sign of $\mathrm{dM}^{*} / \mathrm{dx}^{*}$, which, 
as seen in Eq. (30), is itself a function of $\mathrm{du}_{\mathrm{s}}^{*} / \mathrm{dx}^{*}$ and $\mathrm{dT}_{\mathrm{s}}^{*} / \mathrm{dx}^{*}$.

Analysis of the implications of assumptions on the sign of $\mathrm{dM}^{*} / \mathrm{dx}^{*}$ reveals that the overall problem of determining $u_{p}^{*}, u_{s}^{*}, T_{s}^{*}, \dot{Q}_{d}^{*}, \dot{M}^{*}$, and $\dot{M}_{d}$ as functions of $x^{*}$ can be presented in the following concise format.

Define:

$$
\begin{aligned}
\beta \equiv\left(T_{\mathrm{LAYER}}^{*} / \mathrm{T}_{\mathrm{s}}^{*}-1\right)=\left(1-\mathrm{T}_{\mathrm{s}}^{*} / \mathrm{T}_{\mathrm{LAYER}}^{*}\right) /\left(\mathrm{T}_{\mathrm{s}}^{*} / \mathrm{T}_{\mathrm{LAYER}}^{*}\right) \\
\Lambda_{1} \equiv \omega_{1} / u_{\mathrm{p}}^{*} \\
\Lambda_{2} \equiv \omega_{2}\left(\mathrm{~T}_{\mathrm{s}}^{*}+1.55\right)^{0.35}\left(\mathrm{u}_{\mathrm{p}}^{*}-\mathrm{u}_{\mathrm{s}}^{*}\right)^{3 / 2} /\left(\mathrm{T}_{\mathrm{s}}^{* 1 / 2} \mathrm{u}_{\mathrm{p}}^{*}\right) \\
\Lambda_{3} \equiv \omega_{3} \mathrm{~T}_{\mathrm{s}}^{* 1 / 2}\left(\mathrm{~T}_{\mathrm{s}}^{*}+1.55\right)^{0.35}\left(\mathrm{u}_{\mathrm{p}}^{*}-\mathrm{u}_{\mathrm{s}}^{*}\right)^{3 / 2} /\left(\mathrm{u}_{\mathrm{p}}^{*} \mathrm{u}_{\mathrm{s}}^{*} \mathrm{x}^{* 2}\right) \\
\quad=\left(\omega_{3} / \omega_{2}\right) \Lambda_{2} \mathrm{~T}_{\mathrm{s}}^{*} /\left(\mathrm{u}_{\mathrm{s}}^{*} \mathrm{x}^{* 2}\right) \\
\Lambda_{4} \equiv \omega_{4}[\beta /(1+\beta)] / \mathrm{u}_{\mathrm{s}}^{*} \\
\left.\Lambda_{5} \equiv \omega_{5}\left(\mathrm{~T}_{\mathrm{s}}^{*}-0.993\right) \mathrm{h}^{*}\left(\mathrm{~T}_{\mathrm{s}}^{*}, \mathrm{u}_{\mathrm{s}}^{*}, \mathrm{u}_{\mathrm{p}}^{*} ; \lambda_{1}, \lambda_{2}\right) /\left(u_{\mathrm{p}}^{*} \mathrm{x}^{* 2}\right)\right]
\end{aligned}
$$

where $\omega_{1}, \omega_{2}, \omega_{3}, \omega_{4}, \omega_{5}$, and $h^{*}$ are given in Eqs. (32), (33), (35), (36), (39), and (40), respectively. Then:

$$
\begin{aligned}
& \text { If } \beta \leq 0 \text { and }\left[\mathrm{u}_{\mathrm{s}}^{*} / \mathrm{x}^{*}+\Lambda_{3}+\Lambda_{4}+(\sigma / 2) \Lambda_{5}\right] \leq 0 \text { : } \\
& \qquad \begin{array}{c}
\mathrm{du}_{\mathrm{s}}^{*} / \mathrm{dx} \mathrm{x}^{*}=-\mathrm{u}_{\mathrm{s}}^{*} / \mathrm{x}^{*}+\Lambda_{3}+\Lambda_{4}-(\sigma / 2) \Lambda_{5} \\
\mathrm{dT}_{\mathrm{s}}^{*} / \mathrm{dx} \mathrm{x}^{*}=-\left(\mathrm{T}_{\mathrm{s}}^{*} / \mathrm{u}_{\mathrm{p}}^{*}\right) \Lambda_{5}
\end{array}
\end{aligned}
$$

Else:

$$
\begin{aligned}
& \mathrm{du}_{\mathrm{s}}^{*} / \mathrm{dx} \mathrm{x}^{*}=\left[-(1-\sigma \beta) \mathrm{u}_{\mathrm{s}}^{*} / \mathrm{x}^{*}+(1+\sigma \beta)\left(\Lambda_{3}+\Lambda_{4}\right)-(\sigma / 2) \Lambda_{5}\right] / \\
& {[1+(\sigma / 2) \beta]} \\
& \mathrm{dT}_{\mathrm{s}}^{*} / \mathrm{dx}^{*}=\left[\beta\left(\mathrm{u}_{\mathrm{s}}^{*} / \mathrm{x}^{*}+\Lambda_{3}+\Lambda_{4}\right)-\Lambda_{5}\right]\left(\mathrm{T}_{\mathrm{s}}^{*} / \mathrm{u}_{\mathrm{p}}^{*}\right) /[1+(\sigma / 2) \beta]
\end{aligned}
$$


Whether or not Eq. (57) is satisfied:

$$
\begin{aligned}
& \mathrm{du}_{\mathrm{p}}^{*} / \mathrm{dx} \mathrm{x}^{*}=\Lambda_{1}-\Lambda_{2} \\
& \mathrm{~d} \dot{\mathrm{Q}}_{\mathrm{d}}^{*} / \mathrm{dx}{ }^{*}=-\Lambda_{5} \mathrm{x}^{* 2} \\
& \dot{\mathrm{M}}^{*}=\text { from Eq. }(29) \\
& \dot{\mathrm{M}}_{\mathrm{d}}=\text { from Eq. }(50)
\end{aligned}
$$

where $\sigma$ is given in Eq. (27). From Eq. (30) and the above results it follows that:

when the condition of (57) is satisfied:

$$
\mathrm{d}^{*} / \mathrm{dx} \mathrm{x}^{*}=\left(\mathrm{x}^{*} / \mathrm{T}_{\mathrm{s}}^{*}\right)\left[\mathrm{u}_{\mathrm{s}}^{*} / \mathrm{x}^{*}+\Lambda_{3}+\Lambda_{4}+(\sigma / 2) \Lambda_{5}\right] \leq 0
$$

when the condition of (57) is not satisfied:

$$
\mathrm{d}^{*} / \mathrm{dx} \mathrm{x}^{*}=\left(\mathrm{x}^{*} / \mathrm{T}_{\mathrm{s}}^{*}\right)\left[\mathrm{u}_{\mathrm{s}}^{*} / \mathrm{x}^{*}+\Lambda_{3}+\Lambda_{4}+(\sigma / 2) \Lambda_{5}\right] /[1+(\sigma / 2) \beta]>0
$$

Thus, elevations and scenarios where the condition of (57) is satisfied correspond to those elevations below the interface (since $\beta \leq 1$ means that $\mathrm{T}_{\mathrm{L}}^{*} \mathrm{YER} \leq \mathrm{T}_{\mathrm{S}}^{*}$ ) where there is outflow of gases from the spray cone (since $\left.\mathrm{dM}^{*} / \mathrm{dx}^{*} \leq 0\right)$.

For flow conditions corresponding to ICOND 1 and ICOND 6 there is entrainment into the spray cone (i.e., $\mathrm{dM}^{*} / \mathrm{dx}^{*}>0$ ) along its entire length and the condition of (57) is never satisfied. For ICOND 3, 4, and 5, there is always a portion of the length of the lower layer spray cone where Eq. (57) will be satisfied. Finally, for ICOND 2, Eq. (57) may or may not be satisfied in an elevation interval of the lower layer.

The values of $u_{p}^{*}, u_{s}^{*}, T_{s}^{*}, \dot{Q}_{d}^{*}, \dot{M}^{*}$, and $\dot{M}_{d}$ at an arbitrary $x^{*}$ of interest are obtained by integrating Eqs. (57)-(63) for $u_{p}^{*}, \dot{Q}_{d}^{*}, u_{s}^{*}$, and $T_{s}^{*}$, and then using Eqs. (29) and (50) to determine $\dot{\mathrm{M}}^{*}$ and $\dot{\mathrm{M}}_{d}$. The integrations are from the initial value $x^{*}=x_{W}^{*}$. Initial values of $u_{p}^{*}, u_{s}^{*}, T_{s}^{*}$, and $\dot{Q}_{d}^{*}$ are required to carry out the calculation. The initial value of $\dot{Q}_{d}^{*}$ is given by $E q . ~(48)$. Using Eqs. (16) and (17), the other three initial values are 


$$
\text { at } \begin{aligned}
\mathrm{x}^{*}=\mathrm{x}_{\mathrm{W}}^{*}=\mathrm{x}_{\mathrm{W}} / \mathrm{D}_{\mathrm{W}}=1 /[2 \tan (\theta / 2)]>0: \\
\mathrm{u}_{\mathrm{p}}^{*}=1 \\
\mathrm{u}_{\mathrm{s}}^{*}=\mathrm{u}_{\mathrm{s} 0} / \mathrm{u}_{\mathrm{p} 0}=0 \\
\mathrm{~T}_{\mathrm{s}}^{*}=\mathrm{T}_{\mathrm{LAYER}}^{*}
\end{aligned}
$$

\section{SOLVING THE PROBLEM FOR THE SPRAY CONE ENVELOPE}

A procedure for solving the problem of flow in the spray cone is presented and discussed below and summarized in the flow diagram of Figure 4.

\section{The Solution Near Elevations where $u_{s}^{*}=0$}

In view of the complexity of Eqs. (51)-(69), the indicated integrations of the equation set must be carried out numerically. However, some care is required since it is evident from Eqs. (54) and (55) that $\Lambda_{3}$ and $\Lambda_{4}$, and therefore some of the right sides of Eqs. (55)-(63), are singular at elevations where $u_{s}^{*}=0$. As indicated in Eq. (68), the initial elevation $x^{*}=x_{W}^{*}$ is always such an elevation. The other such elevations will occur for ICOND 4 or 5 ; in particular, at the elevations of the jet penetration depth, designated as $\mathrm{x}^{*}=$ $\mathrm{x}_{\delta}^{*}$. The solution variables do indeed exhibit singular behavior at such elevations, the most significant involving a jump in $\mathrm{T}_{\mathrm{s}}^{*}$ from its computed value immediately above the $\mathrm{x}_{\delta}^{*}$ elevation, i.e., at $\mathrm{x}^{*}=\mathrm{x}_{\delta}^{*-}$, to the value $\mathrm{T}_{\mathrm{s}}^{*}=$ $\mathrm{T}_{\mathrm{LAYER}}^{*}$ immediately below the $\mathrm{x}_{\delta}^{*}$ elevation, i.e., at $\mathrm{x}^{*}=\mathrm{x}_{\delta}^{*+}$. As suggested in earlier discussion, the problem near $\mathrm{x}^{*}=\mathrm{x}_{\delta}^{*}$ and for $\mathrm{x}^{*} \geq \mathrm{x}_{\delta}^{*}$ can be treated in a manner which is completely analogous to the problem near $x^{*}=x_{W}^{*}$ and for $\mathrm{x}^{*} \geq \mathrm{x}_{\mathrm{W}}^{*}$.

\section{The Solution Near $x^{*}=x_{W}^{*}$}

Analysis of the problem reveals that the singularity at $\mathrm{x}^{*}=\mathrm{x}_{\mathrm{W}}^{*}$ is removable. In particular, near $\mathrm{x}^{*}=\mathrm{x}_{\mathrm{W}}^{*}$ the values of $\mathrm{u}_{\mathrm{p}}^{*}, \mathrm{~T}_{\mathrm{s}}^{*}, \beta$, and $\dot{\mathrm{Q}}_{\mathrm{d}}^{*}$ are approximated

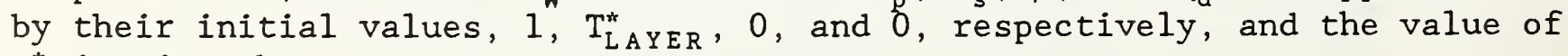
$u_{s}^{*}$ is given by

$$
\begin{array}{r}
\lim _{x^{*} \downarrow x_{W}^{*}} u_{s}^{*}=\left[2 \omega_{3} T_{L A Y E R}^{*}{ }^{1 / 2}\left(T_{L A Y E R}^{*}+1.55\right)^{0.35} / x_{W}^{* 2}\right]^{1 / 2}\left(x^{*}-x_{W}^{*}\right)^{1 / 2}+ \\
o\left(x^{*}-x_{W}^{*}\right)^{1 / 2}
\end{array}
$$

\section{Continuing the Solution to Arbitrary $x^{*}$}

For some specified small value $\epsilon>0$, Eq. (70) would be used to estimate the solution to the problem from $\mathrm{x}^{*}=\mathrm{x}_{\mathrm{W}}^{*}$ to $\mathrm{x}^{*}=\mathrm{x}_{\mathrm{W}}^{*}+\epsilon$. For $\mathrm{x}^{*}>\mathrm{x}_{\mathrm{W}}^{*}+\epsilon$, the solution would be obtained directly from Eqs. (51)-(63), where the integrations would be carried out numerically. The integrations would be continued 
to the smaller of following two values of $x^{*}: x^{*}=x_{F L O O R}^{*}$, corresponding to the floor elevation, or $x^{*}=x_{\delta}^{*}$ corresponding to an elevation where $u_{s}^{*} \downarrow 0$. In the event that a $x_{\delta}^{*}$ value was identified (where $x_{\delta}^{*}<x_{F L O O R}^{*}$ ), the solution would then be continued by appropriately re-initializing the problem at $\mathrm{x}^{*}=$ $\mathrm{x}_{\delta}^{*}$ and integrating the equation set to $\mathrm{x}^{*}=\mathrm{x}_{\mathrm{FLOOR}}^{*}$.

An ICOND 1 scenario is identified directly from the geometry of the sprinkler/layer configuration. For this scenario the solution to the problem is straight-forward and numerical integrations would be carried out to $\mathrm{x}^{*}=$ $\mathrm{x}_{\mathrm{F} L O O R}^{*}$ without any special considerations. Note that from the solutions obtained, the particular solution value $\mathrm{Q}_{d}^{*}\left(\mathrm{x}^{*}=\mathrm{x}_{\mathrm{F} \text { LOOR }}^{*}\right)$ will be required in the analysis of a later section.

For ICOND 2-6 scenarios, integration to the elevation of the interface, designated as $x^{*}=x_{I N I}^{*}$, is carried out, again with no special considerations. When Eq. (57) is satisfied at $\mathrm{x}_{\mathrm{IN} \mathrm{T}}^{*}$ an ICOND 3 or 4 scenario is indicated. When Eq. (57) is not satisfied at $\mathrm{x}_{\mathrm{INI}}^{*}{ }^{+}$an ICOND 2, 5, or 6 scenario is indicated. The remainder of this section will establish solution procedures which can be used for ICOND 2-6 scenarios.

ICOND 2-6 Scenarios: Identifying the Value of $x_{\delta}^{*}<x_{F L O O R}^{*}$, When It Exists, and Determining the Solution Variables in the Range $\mathrm{x}_{\mathrm{INT}}^{*}<\mathrm{x}^{*} \leq \mathrm{x}_{\mathrm{FLOOR}}^{*}$

General Considerations. For a possible ICOND 2, 3, 4, 5, or 6 scenario, it is not known a priori whether a value $x_{\delta}^{*}<x_{\text {FLOOR }}^{*}$ exists (i.e., ICOND 4 or 5 ). Furthermore, if such a $x_{\delta}^{*}$ does exist the solution for $T_{s}^{*}$ is discontinuous at $x_{\delta}^{*}$. When integrating the equation set, it is generally required that the solution procedure be capable of determining $x_{\delta}^{*}$ and all solutions of the unknown variables to any specified accuracy.

The solution strategy adopted here depends on the following observation:

Assume that there is an elevation $x_{M}^{*}<x_{F L O O R}^{*}$, where Eq. (57) is first satisfied. Assume further that integration of Eqs. (51)-(63) from $x_{I N T}^{*}$ resulted in the identification of this elevation. Then it can be shown from the equation set that $\mathrm{du}_{\mathrm{s}}^{*} / \mathrm{dx}^{*}<0$ uniformly in the range $\mathrm{x}_{\mathrm{M}}^{*}<\mathrm{x}^{*} \leq \mathrm{x}_{\delta}^{*}$, if $\mathrm{x}_{\delta}^{*}<$ $x_{F L O O R}^{*}$ exists, or in the range $x_{M}^{*}<x^{*} \leq x_{F L O O R}^{*}$ if $x_{\delta}^{*}<x_{F L O O R}^{*}$ does not exist. Accordingly, because $u_{s}^{*}$ decreases monotonically with increasing $x^{*}$ it is generally possible to continue the solution of the initial value problem in a range which includes the possible singular elevation $\mathrm{x}_{\delta}^{*}$ by exchanging dependent and independent variables $x^{*}$ and $u_{s}^{*}$ and integrating the revised equation set from $u_{s}^{*}=u_{s}^{*}\left(x_{M}^{*}\right)$ to $u_{s}^{*}=0$. The revised equation set (only used if $\mathrm{Eq}$. (57) is satisfied), which replaces Eqs. (60)-(63) is:

$$
\begin{aligned}
& \mathrm{dx}^{*} / \mathrm{du}_{\mathrm{s}}^{*}=1 /\left[-\mathrm{u}_{\mathrm{s}}^{*} / \mathrm{x}^{*}+\Lambda_{3}+\Lambda_{4}-(\sigma / 2) \Lambda_{5}\right] \\
& \mathrm{dT}_{\mathrm{s}}^{*} / \mathrm{du}_{\mathrm{s}}^{*}=-\left(\mathrm{T}_{\mathrm{s}}^{*} / \mathrm{u}_{\mathrm{p}}^{*}\right) \Lambda_{5}\left(\mathrm{dx} \mathrm{x}^{*} / \mathrm{du}_{\mathrm{s}}^{*}\right) \\
& d u_{p}^{*} / d u_{s}^{*}=\left(\Lambda_{1}-\Lambda_{2}\right)\left(d x^{*} / d u_{s}^{*}\right)
\end{aligned}
$$




$$
\mathrm{dQ}_{\mathrm{d}}^{*} / \mathrm{du}_{\mathrm{s}}^{*}=-\Lambda_{5} \mathrm{x}^{* 2}\left(\mathrm{dx}^{*} / \mathrm{du}_{\mathrm{s}}^{*}\right)
$$

If a value $x^{*}\left(u_{s}^{*}\right)>x_{F L O O R}^{*}$ is identified in the course of the indicated integration, then $a u_{s}^{*}=0$ value above the floor cannot exist. Under such a circumstance it is clear that no value $\mathrm{x}_{\delta}^{*}<\mathrm{x}_{\mathrm{FLOOR}}^{*}$ is possible, and the equation set in its original form is integrated again from $x_{I N T}^{*}$ to $x_{F L O O R}^{*}$. Since it is now known that no singular $x_{\delta}^{*}$ value exists in this range, the latter integration will proceed without difficulty and the solution to the problem can be completed.

If the above-indicated integration of the revised equation set is completed and $x^{*}\left(u_{s}^{*}=0\right)<x_{F O O R}^{*}$, then $x_{\delta}^{*} \equiv x^{*}\left(u_{s}^{*}=0\right)$ and the values of all variables at $u_{s}^{*}=0$ are identified as the values of these variables at $x_{\delta}^{*-}$. When this occurs, the integration of the equation set in its original form is then continued from $\mathrm{x}_{\delta}^{*+}$ to $\mathrm{x}_{\mathrm{FLOOR}}^{*}$. Since it is now known that no singular $\mathrm{x}_{\delta}^{*}$ value exists in this latter range, the integration with appropriate initial conditions will proceed without difficulty and the solution to the problem can be completed. Further discussion on this final stage of integration, when $x^{*}$ $>\mathrm{x}_{\delta}^{*}$, is discussed below.

ICOND 2, 5, or 6 Scenarios. If Eq. (57) is not satisfied at $\mathrm{x}_{\mathrm{INT}}^{*}$, then an ICOND 2, 5, or 6 scenario is involved. (At this stage of the integration these three possible flow scenarios are indicated by ICOND 7 in Figure 4.) Then integration of the original equation set is continued between $\mathrm{x}_{\mathrm{IN} T}^{*}$ and $\mathrm{x}_{\mathrm{FLOOR}}^{*}$. At an intermediate stage of this integration the $\mathrm{x}_{\mathrm{M}}^{*}$ elevation that may exist would be identified. If no $x_{M}^{*}$ is identified then a ICOND 6 scenario is indicated and the solution to the problem is completed.

If the integration reveals the existence and the value of $x_{M}^{*}<x_{F L O O R}^{*}$ an ICOND 2 or 5 scenario is indicated. Then integration of the original equation set is stopped at the $x_{M}^{*}$ elevation and the values of all variables there are identified. Integration with the revised equation set, Eqs. (71)-(74), is then continued from $x_{M}^{*}$. Finally, in accordance with the ideas outlined above, the integration proceeds to $\mathrm{x}^{*}=\mathrm{x}_{\mathrm{FLOOR}}^{*}$ and the solution to the problem is completed.

ICOND 3 or 4 Scenarios. If Eq. (57) is satisfied at $\mathrm{x}_{\mathrm{INT}}^{*}$, then an ICOND 3 or 4 scenario is indicated and $x_{I N T}^{*}$ is identical to the $x_{M}^{*}$ elevation. (At this stage of the integration the two possible flow scenarios are indicated by ICOND 8 in Figure 4.) Integration of the problem with the revised equation set, Eqs. (71)-(74), is then initiated and, in accordance with the ideas outlined above, the integration proceeds to $\mathrm{x}^{*}=\mathrm{x}_{\mathrm{FLOOR}}^{*}$ and the solution to the problem is completed.

The Solution For $\mathrm{x}^{*}>\mathrm{x}_{\delta}^{*}$

For ICOND 4 or 5 and for $x^{*}>x_{\delta}^{*}$, the above-indicated solution is obtained by solving a new initial value problem which involves the original equation set. 
The variables $u_{p}^{*}, u_{s}^{*}$, and $\dot{Q}_{d}^{*}$ are initialized at their previously-computed $x^{*}=$ $\mathrm{x}_{\delta}^{*-}$ values and the variable $\mathrm{T}_{s}^{*}$ is initialized at the value $\mathrm{T}_{\mathrm{LAYER}}^{*}$. According to the above definition of $x_{\delta}^{*}$, note that $u_{s}^{*}\left(x_{\delta}^{*-}\right)=0$.

The equation set has a singularity at $\mathrm{x}^{*}=\mathrm{x}_{\delta}^{*}$. As in the case of the $\mathrm{x}^{*}=\mathrm{x}_{\mathrm{W}}^{*}$ singularity, this one is also removable. In particular, near $\mathrm{x}^{*}=\mathrm{x}_{\delta}^{*}$ the values $u_{p}^{*}$ and $\dot{Q}_{d}^{*}$ are approximated by their values at $\mathrm{x}^{*}=\mathrm{x}_{\delta}^{*-} ; \mathrm{T}_{\mathrm{s}}^{*}$ and $\beta$ are assigned the values $T_{L A Y E R}^{*}$ and 0 , respectively; and the value of $u_{s}^{*}$ is given by

$$
\begin{array}{r}
\lim _{x^{*} \downarrow x_{\delta}^{*}} u_{s}^{*}=\left[2 \omega_{3} T_{\text {LAYER }}^{*}{ }^{1 / 2}\left(T_{\text {LAYER }}^{*}+1.55\right)^{0.35} u_{p}^{*}\left(x_{\delta}^{*}\right)^{1 / 2} / x_{\delta}^{*}\right]^{1 / 2}\left(x^{*}-x_{\delta}^{*}\right)^{1 / 2} \\
+o\left(x^{*}-x_{\delta}^{*}\right)^{1 / 2}
\end{array}
$$

For some specified small value $\epsilon>0$, the above values would be used to estimate the solution to the problem from $\mathrm{x}^{*}=\mathrm{x}_{\delta}^{*}$ to $\mathrm{x}^{*}=\mathrm{x}_{\delta}^{*}+\epsilon$. For $\mathrm{x}_{\delta}^{*}+\epsilon$ $<\mathrm{x}^{*} \leq \mathrm{x}_{\mathrm{F} \text { LOOR }}^{*}$, the solution would be obtained directly from Eqs. (71) $-(74)$. The indicated integration would proceed without difficulty since no further singularities are possible.

\section{Summary of the Solution Procedure}

The above procedure for solving Eqs. (51)-(69) in the range $x_{W}^{*} \leq x^{*} \leq x_{F L O O R}^{*}$ is slimmarized in the flow diagram of Figure 4.

CALCULATING THE LOWER LAYER ENTRAINMENT RATE BETWEEN THE INTERFACE AND $x_{\delta}^{*}$ IN A FIGURE la SCENARIO

Results from a Related Problem: Jets and Plumes with Reversed, Purely Buoyant Body Forces

Consider the problem of a fluid jet or plume of one density penetrating a fluid layer with a different density $\rho_{\mathrm{L}}$, where the density difference is such that the buoyant forces on the jet or plume fluid is in the direction to oppose its motion. Different aspects of the problem were studied experimentally in references [6] (see Figure 5a) and [7] (see Figure 5b) where the fluids used for the jet or plume and for the layer were fresh water and salt water of different densities.

The result obtained in [6] was an estimate for $\delta_{p}$, the penetration depth into the layer of the original "top-hat-profile" jet used in the experiments.

Define the Froude number, Fr, as in [6]

$$
F r=u /\left\{g\left[\left|\rho_{L}-\rho\right| / \rho\right] D / 2\right\}^{1 / 2}
$$


where $u, D$, and $\rho$ are the velocity, diameter, and density, respectively, of the jet at penetration. Then it was found in [6] that $\delta_{p}$ can be obtained from

$$
2 \delta_{\mathrm{p}} / \mathrm{D}=\left\{\begin{array}{l}
0 \quad \mathrm{Fr} \leq 1.1 \\
3.69(\mathrm{Fr}-1.1)^{0.87} \quad \mathrm{Fr}>1.1
\end{array}\right.
$$

The Eq. (77) estimate is from [4]. It is a curve fit to the data of [6]. It highlights the experimental result, consistent with observations in [7], that the dimensionless penetration depth, $\delta_{p} / D$, is negligible for Fr less than approximately 1 .

For tests with the configuration of Figure $3 a$, it was found in [7] that $\dot{\mathrm{M}}_{E N T}$, the rate of mass entrained by the reversed plume flow from the layer into which the plume is penetrating, is

$$
4 \dot{\mathrm{M}}_{\mathrm{ENT}} /\left[\rho_{\mathrm{L}} \mathrm{D}^{2} \mathrm{u}\right]=2.44\left(\rho / \rho_{\mathrm{L}}\right)^{1 / 2} \mathrm{Fr}^{3}
$$

Eq. (78) is from [4]. It is a revised version of the original result of [7]. It is based on the assumptions that 1) at interface penetration the plume has identical dimensionless Gaussian velocity and density-defect profiles; and 2) $\dot{M}_{E N T}$ is identical to the entrainment that would result from a penetrating "top-hat-profile" jet with the same mass, momentum, and buoyancy fluxes.

\section{Using the Purely-Buoyant-Flow Results to Predict $\dot{\mathrm{M}}_{\mathrm{ENT}}$ Due to the Sprinkler- Driven Gas Jet of the Figure 1a Scenario}

The flow dynamics of the reference [6] and [7] experiments are very similar to the flow dynamics in the lower layer of a ICOND 3 or 4 scenario. However, there are important differences that should be taken account of if one is to adopt for present use the results of Eqs. (77) and (78).

In Eqs. (77) and (78), $\rho$ is the average density of the jet at the elevation of interface penetration. However, in the present situation, prior to any entrainment from the lower layer environment, the density of the jet gases that penetrate the interface is altered from its value at the interface, $\rho_{\mathrm{s}}\left(\mathrm{x}=\mathrm{x}_{\mathrm{INT}}\right)$. This is by virtue of a distributed volumetric heat sink (i.e., the evaporative cooling) between the interface and the penetration depth. To use Eqs. (77) and (78) here, it is therefore evident that an equivalent jet penetration density other than $\rho_{\mathrm{S}}\left(\mathrm{x}=\mathrm{x}_{\mathrm{INT}}\right)$, should be used for $\rho$. It is reasonable to choose this equivalent density to be $\bar{\rho}$, the density associated with the average temperature of the gases in the upward-buoyancy spray cone, $\overline{\mathrm{T}}$, before any mixing with the entrained lower-layer gases.

The results of Eq. (77) and (78) are for a jet with an penetration velocity $u$ at the interface elevation and with only the gravitational body force (the buoyancy force) retarding and changing the direction of the motion of the jet gases between the interface and the penetration depth. Considered here is a jet with penetration velocity $u_{s}\left(x=x_{I N T}\right)$, where, in addition to a retarding 
gravitational buoyancy force, there is a volumetric drop-drag force acting to enhance rather than retard the downward jet gas velocity between the interface and the penetration depth. There is also the additional effect on the $u_{s}$ distribution of contraction of the jet gases due to evaporative cooling. To use Eqs. (77) and (78) here, it is therefore evident that an equivalent jet penetration velocity other than $u_{s}\left(x=x_{I N T}\right)$, should be used for $u$. This equivalent velocity is designated as $u_{E Q}$.

In view of Eq. (76) and the above discussion, $\mathrm{Fr}$ is computed from

$$
F r=u_{E Q} /\left[g\left(\bar{T} / T_{L}-1\right) D_{I N T} / 2\right]^{1 / 2}
$$

where

$$
D_{I N T} \equiv D\left(x=x_{I N T}\right)=2 x_{I N T} \tan (\theta / 2)
$$

With non-zero value of $\delta_{p}$, computed with the methods of the previous sections, now use Eq. (77) to solve for $\mathrm{Fr}$.

$$
\mathrm{Fr}=1.1+0.223\left(2 \delta_{\mathrm{p}} / \mathrm{D}_{\text {IN T }}\right)^{1.15}
$$

and use this in Eq. (76) to find $u_{E Q}$

$$
u_{E Q}=\left[g\left(\bar{T} / T_{L}-1\right) D_{I N T} / 2\right]^{1 / 2} F r
$$

If the previous calculation indicates an ICOND 3 flow condition where the upward buoyant jet in the lower layer impinges on the floor, then $\delta_{p}$ in Eq. (81) should be replaced by $\left(x_{F L O O R}-x_{\text {INT }}\right.$ ).

Replacing $u$ and $\rho$ by $u_{E Q}$ and $\bar{\rho}$, respectively in Eq. (78) and using Eq. (82), the following equation for $\dot{\mathrm{M}}_{E N T}$ is obtained.

$$
\dot{\mathrm{M}}_{\mathrm{ENT}}=2.44 \rho_{\mathrm{REF}}\left(\mathrm{T}_{\mathrm{REF}} / \mathrm{T}_{\mathrm{L}}\right)\left[\mathrm{g}\left(\overline{\mathrm{T}} / \mathrm{T}_{\mathrm{L}}-1\right)\left(\mathrm{D}_{\mathrm{INT}} / 2\right)^{5}\right]^{1 / 2} \mathrm{Fr}^{4}
$$

where $\mathrm{Fr}$ is computed from Eq. (81).

From the definition of $\overline{\mathrm{T}}$ it follows that

$$
\overline{\mathrm{T}}=\mathrm{T}_{\mathrm{U}}+\dot{\mathrm{Q}}_{\mathrm{d}}^{*}\left(\mathrm{x}^{*}=\mathrm{x}_{\delta}^{*} \text { or } \mathrm{x}_{\mathrm{FLOOR}}^{*}\right) /\left[\mathrm{C}_{\mathrm{p}} \dot{\mathrm{M}}^{*}\left(\mathrm{x}^{*}=\mathrm{x}_{\mathrm{INT}}^{*}\right)\right]
$$

where the values of $\dot{\mathrm{Q}}_{\mathrm{d}}^{*}\left(\mathrm{x}^{*}=\mathrm{x}_{\delta}^{*}\right.$ or $\left.\mathrm{x}_{\mathrm{FLOOR}}^{*}\right)$ and $\dot{\mathrm{M}}^{*}\left(\mathrm{x}^{*}=\mathrm{x}_{\mathrm{INT}}^{*}\right)$ were obtained previously. Using Eq. (84) in Eq. (83) finally leads to the desired result for $\dot{\mathrm{M}}_{E N T}$. 
The results obtained by implementing the methods developed in the previous sections can now be used to obtain the net rates of flow of mass, enthalpy, and arbitrary product of combustion, $\mathrm{k}$, to the upper and lower layer as a result of sprinkler operation. These rates are designated by $\dot{\mathrm{M}}_{U}, \dot{\mathrm{M}}_{\mathrm{L}}, \dot{\mathrm{Q}}_{U}, \dot{\mathrm{Q}}_{\mathrm{L}}$, $\dot{\mathrm{P}}_{\mathrm{k}, \mathrm{U}}, \dot{\mathrm{P}}_{\mathrm{k}, \mathrm{L}}$, respectively.

For a given scenario of interest, it is assumed that the problem of Eqs. (51)(69) has been solved for $u_{p}^{*}, u_{s}^{*}, T_{s}^{*}, \dot{Q}_{d}^{*}, \dot{M}^{*}$, and $\dot{M}_{d}$ in the range $x_{W}^{*} \leq x^{*} \leq$ $x_{\text {F }}^{*}$ OOR. Presented below are the equations required to calculate the $\dot{M}_{U}$, $\dot{M}_{L}$, $\dot{\mathrm{Q}}_{U}, \mathrm{Q}_{L}, \dot{\mathrm{P}}_{\mathrm{k}, U}, \dot{\mathrm{P}}_{\mathrm{k}, \mathrm{L}}$, for each of the three possible generic scenarios depicted in Figures $l a, l b$, and $1 c$.

\section{ICOND 3 or 4 Scenarios}

For the ICOND 3 or 4 scenarios, all mass, enthalpy, and products of combustion entrained by the spray cone in the upper layer and all water evaporated in the entire spray cone and its associated enthaply is returned to the upper layer. This is convected via the upward-moving upward-buoyant flow that surrounds the spray cone in the elevation-interval $x_{I N T}^{*} \leq x^{*} \leq x_{\delta}^{*}$ (or the interval $x_{I N T}^{*} \leq x^{*} \leq x_{\text {FOOR }}^{*}$ if there is no $x_{\delta}^{*}<x_{\text {FOOR }}^{*}$ ).

$$
\dot{\mathrm{M}}_{\mathrm{U}}=\dot{\mathrm{M}}_{\mathrm{ENT}}-\dot{\mathrm{Q}}_{\mathrm{d}}\left(\mathrm{x}^{*}=\mathrm{x}_{\delta}^{*} \text { or } \mathrm{x}_{\mathrm{FLOOR}}^{*}\right) / \mathrm{L}_{\mathrm{W}}
$$

where $\dot{\mathrm{M}}_{\text {ENT }}$ is computed from Eqs. (83), (85), and (86).

$$
\begin{aligned}
& \dot{Q}_{U}=\dot{M}_{E N T} C_{p} T_{L}+\dot{Q}_{d}\left(x^{*}=x_{\delta}^{*} \text { or } x_{F L O O R}^{*}\right) \\
& \dot{P}_{H 2 O, U}=\dot{M}_{E N T} c_{H 2 O, L}-\dot{Q}_{d}\left(x^{*}=x_{\delta}^{*} \text { or } x_{F L O O R}^{*}\right) / L_{W} \\
& \dot{P}_{k, U}=\dot{M}_{E N T} c_{k, L} \text { for } k \text { other than } H_{2} O \\
& \dot{M}_{L}=-\dot{M}_{E N T}-\left[\dot{Q}_{d}\left(x^{*}=x_{F L O O R}^{*}\right)-\dot{Q}_{d}\left(x^{*}=x_{\delta}^{*}\right)\right] / L_{W} \\
& \dot{Q}_{L}=-\dot{M}_{E N T} C_{p} T_{L}+\left[\dot{Q}_{d}\left(x^{*}=x_{F L O O R}^{*}\right)-\dot{Q}_{d}\left(x^{*}=x_{\delta}^{*}\right)\right] \\
& \dot{P}_{H 20, L}=-\dot{M}_{E N T} c_{B 20, L}-\left[\dot{Q}_{d}\left(x^{*}=x_{F L O O R}^{*}\right)-\dot{Q}_{d}\left(x^{*}=x_{\delta}^{*}\right)\right] / L_{W} \\
& \dot{P}_{k, L}=-\dot{M}_{E N T} c_{k, L}=-\dot{P}_{k, U} \text { for k other than } H_{2} O
\end{aligned}
$$




\section{ICOND 2, 5, or 6 Scenarios}

In the ICOND 2, 5, or 6 scenarios, all mass, enthalpy, and products of combustion entrained by the spray cone in the upper layer are deposited into the lower layer. Also deposited in the lower layer is all water evaporated in the spray cone and its associated enthaply. As indicated in Figure 3, all of these are introduced to the lower layer at the floor elevation where the spray jet gases impinge on the floor surface.

$$
\begin{aligned}
& \dot{\mathrm{M}}_{\mathrm{U}}=-\dot{\mathrm{M}}\left(\mathrm{x}^{*}=\mathrm{x}_{\mathrm{INT}}^{*}\right) \\
& \dot{Q}_{U}^{\prime}=-\dot{M}\left(x^{*}=x_{I N T}^{*}\right) C_{p} T_{U} \\
& \dot{\mathrm{P}}_{\mathrm{H} 20, \mathrm{U}}=-\dot{\mathrm{M}}\left(\mathrm{x}^{*}=\mathrm{x}_{\mathrm{INT}}^{*}\right) \mathrm{c}_{\mathrm{B} 20, \mathrm{U}} \\
& \dot{\mathrm{P}}_{\mathrm{k}, \mathrm{U}}=-\dot{\mathrm{M}}\left(\mathrm{x}^{*}=\mathrm{x}_{\mathrm{INT}}^{*}\right) \mathrm{c}_{\mathrm{k}, \mathrm{U}} \text { for } \mathrm{k} \text { other than } \mathrm{H}_{2} \mathrm{O} \\
& \dot{\mathrm{M}}_{\mathrm{L}}=\dot{\mathrm{M}}\left(\mathrm{x}^{*}=\mathrm{x}_{\mathrm{INT}}^{*}\right)-\dot{\mathrm{Q}}_{\mathrm{d}}\left(\mathrm{x}^{*}=\mathrm{x}_{\mathrm{F} L O O R}^{*}\right) / \mathrm{L}_{\mathrm{W}} \\
& \dot{Q}_{I}=\dot{M}\left(x^{*}=x_{I N T}^{*}\right) C_{p} T_{U}+\dot{Q}_{d}\left(x^{*}=x_{F L O O R}^{*}\right) \\
& \dot{\mathrm{P}}_{\mathrm{H} 20, \mathrm{~L}}=\dot{\mathrm{M}}\left(\mathrm{x}^{*}=\mathrm{x}_{\mathrm{INT}}^{*}\right) \mathrm{c}_{\mathrm{H} 20, \mathrm{U}}-\dot{\mathrm{Q}}_{\mathrm{d}}\left(\mathrm{x}^{*}=\mathrm{x}_{\mathrm{FLOOR}}^{*}\right) / \mathrm{L}_{\mathrm{W}} \\
& \dot{\mathrm{P}}_{\mathrm{k}, \mathrm{L}}=\dot{\mathrm{M}}\left(\mathrm{x}^{*}=\mathrm{x}_{\mathrm{INT}}^{*}\right) \mathrm{c}_{\mathrm{k}, \mathrm{U}}=-\dot{\mathrm{P}}_{\mathrm{k}, \mathrm{U}} \text { for } \mathrm{k} \text { other than } \mathrm{H}_{2} \mathrm{O}
\end{aligned}
$$

\section{The ICOND 1 Scenario}

In the ICOND 1 scenario the spray cone dynamics have no effect on the upper layer. All mass, enthalpy, and products of combustion entrained by the spray cone from the lower layer and all water evaporated in the spray cone and its associated enthaply are deposited back into the lower layer at the floor elevation where the spray jet gases impinge on the floor surface.

$$
\begin{aligned}
& \dot{\mathrm{M}}_{U}=\dot{\mathrm{Q}}_{\mathrm{U}}=0 \\
& \dot{\mathrm{P}}_{\mathrm{k}, \mathrm{U}}=0 \text { for all } \mathrm{k} \\
& \dot{\mathrm{M}}_{\mathrm{L}}=-\dot{\mathrm{Q}}_{\mathrm{d}}\left(\mathrm{x}^{*}=\mathrm{x}_{\mathrm{FLOOR}}^{*}\right) / \mathrm{L}_{\mathrm{W}} \\
& \dot{\mathrm{Q}}_{\mathrm{L}}=\dot{\mathrm{Q}}_{\mathrm{d}}\left(\mathrm{x}^{*}=\mathrm{x}_{\mathrm{F} L O O R}^{*}\right)
\end{aligned}
$$




$$
\begin{aligned}
& \dot{\mathrm{P}}_{\mathrm{H} 20, \mathrm{~L}}=-\dot{\mathrm{Q}}_{\mathrm{d}}\left(\mathrm{x}^{*}=\mathrm{x}_{\mathrm{F} L O O R}^{*}\right) / \mathrm{L}_{\mathrm{W}} \\
& \dot{\mathrm{P}}_{\mathrm{k}, \mathrm{L}}=0 \text { for } \mathrm{k} \text { other than } \mathrm{H}_{2} \mathrm{O}
\end{aligned}
$$

\section{EXAMPLE CALCULATIONS}

Comparisons of Model Calculations With Experiments and Calculations of [1] and [4] for a Spray in an Ambient Temperature Environment

As noted earlier, under the restrictive conditions of a spray in a uniform, ambient temperature environment the present model equations are essentially identical to the model equations of [1] and [4]. To verify the expected correspondence between calculated results of the two models, the present solution procedure was carried out for selected conditions identical to those indicated in the first row of TABLE II of [1] or TABLES I and II of [4]. (In the nomenclature of [1] and [4] the conditions are: $\gamma=34.45$, i.e., $\theta=$ $120^{\circ} ; \beta=0.01$; and $\left.\xi=0.00075\right)$. Calculations with the present model essentially reproduced the corresponding results of [1] and [4]. As expected, this was in spite of the previously discussed difference in $u_{s}$ initial conditions used in the two models.

The present model also successfully simulated spray-induced jet volume flow rates measured in [4] at $1.52 \mathrm{~m}, 3.04 \mathrm{~m}$ and $5.42 \mathrm{~m}$ below an operating Rockwood $\mathrm{T}$ 4 spray nozzle ${ }^{3}$ deployed in an ambient temperature environment.

\section{Simulated Interactions Between Two-Layer Fire Environments and a Rockwood T-4 Spray Nozzle Flow}

This section presents results of using the present model to simulate the interactions of a sprinkler and a two-layer fire environment. The scenarios simulate the operation of the Rockwood T-4 spray nozzle used in the experiments reported in [1]. This device, like automatic sprinklers used for fire protection, generates a spray by employing a deflector beneath the device to intercept and fragment the solid water jet which flows from the nozzle [1]. The calculations simulate the effects of the sprinkler discharging near the top of the hot upper layer of conjectured two-layer fire environments.

The Rockwood T-4 spray nozzle has the following characteristics [1]:

$$
C_{M}=0.41 ; \quad r=0.096 m / s^{2 / 3} ; \quad D_{N}=0.00635 m
$$

\footnotetext{
${ }^{3}$ The use of trade names are for descriptive purposes only, and should not be construed as endorsement by the National Institute of Standards and Technology or AAMA.
} 
For the test of [1] with the highest nozzle pressure, the flow rate was $0.107 \mathrm{~m}^{3} / \mathrm{s}$ and the measured spray envelope had a diameter of $2.0 \mathrm{~m}, 2.7 \mathrm{~m}$, and $3.1 \mathrm{~m}$ at $1.52 \mathrm{~m}, 3.04 \mathrm{~m}$, and $5.78 \mathrm{~m}$ below the nozzle, respectively. Based on this, the spray envelope for all of these elevations is simulated here by a $45^{\circ}$ cone angle. The following operating condition will be adopted for all calculations

$$
\theta=45^{\circ} ; \quad \dot{\mathrm{V}}_{\mathrm{N}}=0.00107 \mathrm{~m}^{3} / \mathrm{s}
$$

For all calculations the apex of the spray cone is assumed to be at a nozzle exit located $10 \mathrm{~m}$ above the floor. The lower layer is always assumed to be at the ambient temperature $\mathrm{T}_{\mathrm{REF}}$.

Two sets of calculations are carried out. In the first set the upper layer temperature is fixed and the layer interface elevation varies between the $10 \mathrm{~m}$ elevation of the nozzle and the zero elevation of the floor. In the second set of calculations, the layer interface elevation is fixed and the temperature of the upper layer is varied over a wide range of values.

The Spray Nozzle Operating in a 600K Upper Layer. The model was used to simulate the interaction of an operating Rockwood T-4 spray nozzle and a twolayer fire environment with a $600 \mathrm{~K}$ upper layer and a $\mathrm{T}_{\mathrm{REF}}=293 \mathrm{~K}$ ambient temperature lower layer. The results for $\dot{M}_{E N T}$ and $x_{\delta}$ are plotted in Figure 6 as functions of the distance of the interface below the spray nozzle, $x_{I N T}$. The ICOND numbers corresponding to the flow conditions of Figures 2 and 3 are also indicated in Figure 6.

$\mathrm{x}_{\mathrm{INT}}=0$ corresponds to a fire scenario where the interface is at the elevation of the spray nozzle. This leads to an ICOND 1 condition with no effect on the upper layer.

For $0<\mathrm{x}_{\mathrm{INT}} \leq 1.0 \mathrm{~m}$, an ICOND 2 flow condition is predicted. As in Figure 3 , here there is an upward buoyant flow that is established in the lower portion of the lower layer and this impinges on the floor, i.e., $x_{\delta}=10 \mathrm{~m}$. However, because of the "shielding" provided by the far field entrainment into the spray cone immediately below the interface, the lower layer mass entrained into the plume-like lower-layer flow does not return to the upper layer i.e., $\dot{\mathrm{M}}_{\mathrm{ENT}}=0$.

For $1.0 \mathrm{~m}<\mathrm{x}_{\mathrm{INT}}<4.3 \mathrm{~m}$ the model predicts an ICOND 5 flow condition (see Figure 3). As in the ICOND 2 flow condition, the flow penetrating the interface is all mixed into the lower layer. Here, the upward buoyant plume in the lower layer lifts off the floor and $\mathrm{x}_{\delta}$ becomes less than $10 . \mathrm{m}$. However, as required by definition of the geometry, $x_{\delta}$ is always greater than $\mathrm{x}_{\mathrm{INT}}$. As with the ICOND 2 flow condition, the upward buoyant plume flow in the lower layer is still prevented from entering the upper layer and the $\dot{\mathrm{M}}_{\mathrm{ENT}}$ = 0 result persists.

For $4.3 \mathrm{~m}<\mathrm{x}_{\mathrm{INT}} \leq 8.9 \mathrm{~m}$ the model predicts an ICOND 4 flow condition (see Figure 2). At this stage all upward buoyant flow in the lower layer, involving a relatively large entrained mass flow rate ranging from approxi- 
mately $\dot{\mathrm{M}}_{\mathrm{ENT}}=80$ to $370 \mathrm{~kg} / \mathrm{s}$, is predicted to return to the upper layer. Therefore, for the specified upper layer temperature and for the assumed characteristics of the spray device, the model predicts an abrupt and relatively massive growth of the upper layer as the upper layer thickness grows beyond $4.3 \mathrm{~m}$.

For $8.9 \mathrm{~m}<\mathrm{x}_{\text {INT }}<10 . \mathrm{m}$ the model predicts an ICOND 3 flow condition (see Figure 2) where all the penetrating flow and the flow entrained from the lower layer is returned to the upper layer. Here the magnitude of $\dot{\mathrm{M}}_{\mathrm{ENT}}$ continues to increase with continued increase in the upper layer thickness. Note that in this range the upward buoyant plume again impinges on the floor and, as before, $\mathrm{x}_{\delta}=10 \mathrm{~m}$.

The Effect of the Nozzle Spray Penetrating a 5.m Thick Upper Layer. The model was also used to simulate the interaction of an operating Rockwood T-4 spray nozzle and a two-layer fire environment with a $5 \mathrm{~m}$ upper layer thickness and with different upper layer temperatures ranging from $600 \mathrm{~K}$ to $300 \mathrm{~K}$. The lower layer temperature is again fixed at $\mathrm{T}_{\mathrm{REF}}=293 \mathrm{~K}$. The results for $\dot{\mathrm{M}}_{\mathrm{ENT}}$ and $\mathrm{x}_{\delta}$ are plotted in Figure 7 as functions of the upper layer temperature. As in the presentation of the previous results, the ICOND numbers corresponding to the flow conditions sketched in Figures 2 and 3 are also indicated in the figure.

For $300 \mathrm{~K} \leq \mathrm{T}_{\mathrm{U}}<425 \mathrm{~K}$, ICOND 2 or 3 flow conditions are seen to prevail and none of the upward buoyant flow entrainment in the lower layer is returned to the upper layer, i.e., $\dot{\mathrm{M}}_{\mathrm{ENT}}=0$. As the upper layer temperature increases beyond $\mathrm{T}_{\mathrm{U}}=425 \mathrm{~K}$, the situation changes abruptly as upward buoyant flow in the lower layer is able to enter the upper layer. As seen in the figure, for the specified parameters, when the upper layer goes beyond this "threshold" temperature a significant flow rate of approximately $\dot{M}_{E N T}=80 \mathrm{~kg} / \mathrm{s}$ of entrained lower layer flow is predicted to be deposited into the upper layer. As $\mathrm{T}_{\mathrm{U}}$ rises from $425 \mathrm{~K}$ to $600 \mathrm{~K}, \dot{\mathrm{M}}_{\mathrm{ENT}}$ increases to approximately $112 \mathrm{~kg} / \mathrm{s}$ and the flow condition remains at ICOND 4.

\section{Summary of the Example Calculations - Ceiling Venting to Enhance the Effec- tiveness of Sprinkler Systems}

The above example calculations illustrate some of the important effects of the interaction of a sprinkler spray and a two-layer fire environment. The phenomenon highlighted by the calculations is the abrupt and large change in sprinkler/layer interaction that comes about as an upper layer increases in thickness beyond a critical thickness (for a given upper layer temperature) or increases in upper layer temperature beyond a critical temperature (for a given upper layer thickness). When the layer does not exceed the critical values the sprinkler spray is predicted to have a relatively small effect on the upper layer. In particular, the model predicts that the spray simply entrains and extracts a relatively small flow of upper gases and deposits it into the lower layer. When the critical values are exceeded, the model predicts that a very large rate of relatively cool lower layer gases, of the order of several tens to a few hundred $\mathrm{kg} / \mathrm{s}$ in the example calculations, is 
entrained and transferred to the upper layer. This would be accompanied by a redeposition into the upper layer of all of those upper layer gases, cooled and humidified by spray drop evaporation, which are continuously extracted from the upper layer by the action of the spray cone entrainment there.

The net result of the above predicted sprinkler/layer interaction would be a very large rate of growth in the thickness of the upper layer, a growth that in practice could lead to rapid and complete smoke filling of even the largest compartments of fire origin.

From the above results and discussion, it would appear that control or delay of the temperature and/or thickness of the upper layer to below-critical levels would lead to predictable design-response sprinkler/fire interactions, i.e., sprinkler/fire interactions which do not significantly deviate from design conditions. For example, it is possible that the relatively prompt use of ceiling venting could provide the suggested desirable smoke layer control. Indeed, use of ceiling venting to provide such control, without significant smoke logging, could be the basis of a strategy of co-ordinated sprinkler/vent design leading to effective fire control/suppression in compartments of fire origin.

\section{USING THE SPRINKLER/LAYER INTERACTION MODEL IN LAVENT}

The full implications of the sprinkler/layer model developed here can only be assessed within the context of simulations invclving a complete compartment fire model. One likely candidate model is the two-layer zone compartment fire model computer code LAVENT (Link Actuated VENTs) [8,9]. LAVENT simulates the development of the fire environment in a compartment of fire origin outfitted with fusible-link-actuated ceiling vents and sprinklers. LAVENT simulates the environment in the fire compartment up to the time that the first sprinkler link fuses and the water flow from the actuated sprinkler nozzle is initiated.

By including the present sprinkler/layer interaction model in LAVENT, the revised compartment fire model would be able to simulate the fire environment beyond the time of first sprinkler operation, including the effects of subsequent actuation of additional ceiling vents and/or sprinkler nozzle flows. A prototype version of such a revised LAVENT fire model is now under development. The new fire model will be called LAVENTS (Link Actuated VENTs and Sprinklers).

\section{SUMMARY AND CONCLUSIONS}

A mathematical model was developed to simulate the interaction of an isolated operating sprinkler and a two-layer fire environment under arbitrary conditions of sprinkler-nozzle elevation, and upper-and lower-layer thickness and temperature. The sprinkler is characterized by water flow rate, nozzle diameter, and three other measurable device parameters related to: the drop size of the water flow after fragmentation of the nozzle flow stream, the momentum of the stream after fragmentation, and an effective cone angle of the sprinkler spray. The model takes account of all effects of the sprinkler spray as it entrains, drives downward (by aerodynamic drag on the spray 
drops), humidifies, and cools (by drop evaporation) gases from both the high temperature upper layer and the relatively cooler lower layer.

A specific objective of the model was to provide a means of predicting the rates of flow of mass, enthalpy, products of combustion, and evaporated water to each of the two layers as a result of sprinkler operation. An algorithm for such predictions was presented. This is suitable for general use in twolayer zone-type compartment fire models.

The model was exercised in example calculations which simulate the interaction between the spray of a real sprinkler device and both fire and non-fire environments. Limited validation of the model was achieved in the simulation of experiments involving the operation of a spray nozzle flow operating in a uniform, ambient-temperature, non-fire environment [1,4]. Model validation in experiments involving operating sprinkler in fire environments is required.

Example calculations simulated the interaction of an operating Rockwood T-4 spray nozzle and a variety of two-layer fire environments in a $10 \mathrm{~m}$ high space. An important generic phenomenon identified in these calculations was the abrupt and large change in sprinkler/layer interaction that comes about as an upper layer increases in thickness beyond a critical thickness (for a given upper layer temperature) or increases in upper layer temperature beyond a critical temperature (for a given upper layer thickness). When the layer does not exceed the critical values, the sprinkler spray is predicted to result in relatively little mixing between the layers. However, when the critical values are exceeded the model predicts that a very large flow of lower layer gases is transferred to the upper layer by entrainment into the upward buoyant flow that is driven out of the upper layer by direct action of the water spray. The net result of the latter predicted sprinkler/layer interaction would be a very large rate of growth in the thickness of the upper layer, a growth that could lead to rapid and complete smoke filling of even the largest compartments of fire origin.

The above calculation results suggested that control or delay of the temperature and thickness of the upper layer to below-critical levels could be useful in guaranteeing sprinkler/fire interactions, without smoke logging (smoke filling of the entire space), which do not significantly deviate from design conditions. It is possible that the relatively prompt use of ceiling venting could provide the suggested desirable smoke layer control.

The model developed here can only be assessed within the context of a full compartment fire model simulation. Toward the development of such a simulation capability, the sprinkler/layer interaction model is being included in a revised version of the compartment fire model LAVENT (Link Actuated VENTs) $[8,9,10]$. The new fire model will be called LAVENTS (Link Actuated VENTs and Sprinklers).

\section{ACKNOWLEDGEMENT}

The author acknowledges gratefully the American Architectural Manufacturers Association (AAMA) Research Foundation which supported this work. 


\section{NOMENCLATURE}

\begin{tabular}{|c|c|}
\hline$A_{S P R A Y}$ & cross-section area of the spray cone \\
\hline B & constant in Eq. (5) [12.6] \\
\hline$B^{\prime}$ & mass transfer number, Eq. (13) \\
\hline$c_{\mathrm{H} 2 O}, \mathrm{U}, \mathrm{C}_{\mathrm{H} 2 \mathrm{O}, \mathrm{L}}$ & $\begin{array}{l}\text { mass fraction of } \mathrm{H}_{2} \mathrm{O} \text { in upper, lower layer }\left[\left(\mathrm{kg} \text { of } \mathrm{H}_{2} \mathrm{O}\right) /(\mathrm{kg}\right. \\
\text { layer)] }\end{array}$ \\
\hline$c_{k, U}, c_{k, L}$ & $\begin{array}{l}\text { mass fraction of product } \mathrm{k} \text { in upper, lower layer }[(\mathrm{kg} \text { of } \\
\text { product } \mathrm{k}) /(\mathrm{kg} \text { layer })]\end{array}$ \\
\hline$C_{D}$ & drag coefficient \\
\hline $\mathrm{C}_{\mathrm{M}}$ & $\begin{array}{l}\text { ratio of initial momentum of the spray to momentum of the } \\
\text { water flow in the sprinkler nozzle (estimate as } 0.4 \text { ). }\end{array}$ \\
\hline$C_{p}$ & $\begin{array}{l}\text { reference specific heat of air at constant pressure } \\
{[1.004 \mathrm{~kJ} /(\mathrm{kg} \cdot \mathrm{K})]}\end{array}$ \\
\hline D & diameter of the spray cone \\
\hline $\mathrm{D}_{\mathrm{N}}$ & sprinkler nozzle diameter \\
\hline $\mathrm{D}_{\mathrm{W}}$ & diameter of the spray at $\mathrm{x}=\mathrm{x}_{\mathrm{W}}$ \\
\hline $\mathrm{d}$ & volume-mean diameter of the spray drops \\
\hline $\mathrm{F}_{\mathrm{d}}$ & drag force on a single drop \\
\hline Fr & Froude number, Eq. (76) \\
\hline$f\left(\dot{\mathrm{M}}^{*}\right)$ & Eq. (38) \\
\hline$g$ & acceleration of gravity $\left[9.8 \mathrm{~m} / \mathrm{s}^{2}\right]$ \\
\hline h & heat transfer coefficient, Eq. (12) \\
\hline$h^{*}$ & dimensionless h, Eq. (40) \\
\hline $\mathrm{k}$ & thermal conductivity of air at a reference temperature [4] \\
\hline $\mathrm{L}_{\mathrm{W}}$ & latent heat of vaporization of water $\left[2.26\left(10^{3}\right) \mathrm{kJ} / \mathrm{kg}\right]$ \\
\hline$\dot{\mathrm{m}}_{\mathrm{d}}$ & mass rate of water evaporation from a single drop \\
\hline$\dot{\mathrm{M}}_{U}, \dot{\mathrm{M}}_{\mathrm{L}}$ & $\begin{array}{l}\text { net rate of mass flow to the upper, lower layer as a result } \\
\text { of sprinkler operation }\end{array}$ \\
\hline$\dot{\mathrm{M}}_{\mathrm{EN} \mathrm{T}}$ & mass rate of entrainment of the reversed plume flow \\
\hline
\end{tabular}


$\dot{\mathrm{M}}$

$\dot{\mathrm{M}}^{*}$

$\dot{\mathrm{M}}_{\mathrm{d}}$

$\mathrm{N}$

$\mathrm{Nu}$

$\operatorname{Pr}$

$\dot{\mathrm{P}}_{\mathrm{k}, \mathrm{U}}, \dot{\mathrm{P}}_{\mathrm{k}, \mathrm{L}}$

$\dot{\mathrm{Q}}_{\mathrm{U}}, \dot{\mathrm{Q}}_{\mathrm{L}}$

$\dot{\mathrm{q}}_{\mathrm{d}}$

$\dot{Q}_{d}$

$\dot{Q}_{d}^{*}$

$\operatorname{Re}$

$\operatorname{Re}_{M}$

$r$

$\mathrm{T}$

$\overline{\mathrm{T}}$

$\mathrm{T}_{1 / 3}$

$\mathrm{T}_{\mathrm{REF}}$

$\mathrm{T}_{\mathrm{U}}, \mathrm{T}_{\mathrm{L}}$

T L AYER

$\mathrm{T}_{\mathrm{p}}$

$\mathrm{T}_{\mathrm{s}}$

$\mathrm{T}_{\mathrm{s} 0}$

$\mathrm{T}_{\mathrm{SUB}}^{\star \mathrm{k}}$ mass rate of layer gases entrained into the spray cone from $\mathrm{x}_{\mathrm{w}}$ to $\mathrm{x}$

dimensionless value of $\dot{\mathrm{M}}$, Eq. (28)

mass rate of water evaporation from all drops in the spray cone between $x_{W}$ and $x$

number of drops per unit volume in spray cone

hd/k

Prantdl number of air

net rate of flow of product of combustion $k$ to the upper, lower layer as a result of sprinkler operation

net rate of flow of enthalpy plus heat transfer to the upper, lower layer as a result of sprinkler operation

rate of heat transfer to the air from a single drop

rate of heat transfer from the drops to the gas in the spray cone between $x_{W}$ and $x$

dimensionless value of $\dot{Q}_{d}$, Eq. (46)

Reynolds number, Eq. (6)

Reynolds number, Eq. (13)

drop size parameter, Eq. (3); estimate to be $\left[0.084 \mathrm{~m} / \mathrm{s}^{2 / 3}\right]$

absolute temperature of air

average temperature of air in spray cone between $\mathrm{x}_{\mathrm{INT}}$ and $\mathrm{x}_{\delta}$

characteristic value of T, Eq. (7)

reference value of $\mathrm{T}[293 \mathrm{~K}]$

$\mathrm{T}$ of upper, lower layer

$\mathrm{T}$ of layer at the local elevation

absolute temperature of drop surface

$T$ in the free stream of the spray cone

$T_{s}\left(x=x_{W}\right)$

$T_{S U B} / T_{R E F}$ for any subscript $S U B$ 
velocity

$\mathrm{u}_{\mathrm{EQ}}$

$u_{n}$

$u_{p}$

$u_{p 0}$

$u_{R E L}$

$u_{s}$

$u_{s o}$

$u_{p}^{*}, u_{s}^{*}$

$\dot{\mathrm{V}}_{\mathrm{N}}$

$\mathrm{x}$

$\mathrm{X}_{\mathrm{FLOOR}}$

$\mathrm{X}_{\text {IN T }}$

$x_{M}$

$\mathrm{x}_{\mathrm{W}}$

$\mathrm{x}_{\delta}$

$x_{S \cup B}^{*}$

$x^{*}$

y

$\mathrm{y}_{\mathrm{CEIL}}$

$\mathrm{Y}_{F L O O R}$

Y YAYER

$\mathrm{Y}_{S P R I N K}$

$\mathrm{y}_{S P R A Y}$

$\beta$

$\delta_{p}$

$\epsilon$

equivalent velocity of air in spray cone between $\mathrm{x}_{\text {INT }}$ and $\mathrm{x}_{\delta}$ nozzle discharge velocity

velocity of the spray cone drops in the $\mathrm{x}$ direction

$u_{p}\left(x=x_{W}\right)$

$\left|u_{p}-u_{s}\right|$

velocity of air in the spray cone in the $x$ direction

$u_{s}\left(x=x_{W}\right)$

$u_{p} / u_{p 0}, u_{s} / u_{p 0}$

volumetric water discharge rate of the nozzle

distance below the spray cone apex located approximately at $\mathrm{y}_{\text {S PRINK }}$

$x$ at floor, $y_{\text {SPRINK }}-y_{F L O O R}$

$x$ at layer interface, $y_{\text {LAYER }}-y_{F L O O R}$

$\mathrm{x}$ at highest elevation where Eq. (57) is satisfied

$x$ at $y_{S P R A Y}$

$\mathrm{x}$ at jet penetration depth

$\mathrm{x}_{\mathrm{SUB}} / \mathrm{D}_{\mathrm{W}}$ for any subscript $\mathrm{SUB}$

$\mathrm{x} / \mathrm{D}_{\mathrm{W}}$

elevation above a datum elevation

$y$ of the ceiling

$y$ of the floor

$y$ of the layer interface

$y$ of the sprinkler nozzle outlet

$y$ where breakup of the sprinkler outlet stream is completed

Eq. (51)

jet penetration depth, $x_{\delta}-x_{\text {INT }}$

arbitrarily small positive number 
sprinkler spray angle

$\Lambda_{i}, i=1$ to 5 Eqs. (52)-(56)

$\lambda_{1}, \lambda_{2}$

constants, Eqs. (41), (42)

$\mu$

dynamic viscosity of air

$\mu_{1 / 3}$

a characteristic value of $\mu$, Eq. (7)

$\mu_{\mathrm{s}}$

dynamic viscosity of air in the free stream of the spray cone

$\nu \quad$ kinematic viscosity of air

$\nu_{R E F}$

$\nu\left(T=T_{R E F}\right)\left[1.49\left(10^{-5}\right) \mathrm{m}^{2} / \mathrm{s}\right]$

$\omega_{i}, i=1$ to 5

constants: $i=1$, Eq. (32); $i=2$, Eq. (33); $i=3$,

Eq. (35); $i=4, \mathrm{Eq} \cdot(36) ; i=5, \mathrm{Eq} \cdot$ (39)

$\rho$

density

$\bar{\rho}$

$\rho$ associated with $\overline{\mathrm{T}}$

$\rho_{\mathrm{REF}}$

$\rho\left(\mathrm{T}=\mathrm{T}_{\mathrm{REF}}\right)\left[1.2 \mathrm{~kg} / \mathrm{m}^{3}\right]$

$\rho_{\mathrm{W}}$

density of water $\left[1.0\left(10^{3}\right) \mathrm{kg} / \mathrm{m}^{3}\right]$

$\rho_{s}$

density of air in the free stream of the spray cone

$\rho_{\mathrm{U}}, \rho_{\mathrm{L}}$

density of upper, lower layer

$\sigma$

Eq . (27) 


\section{REFERENCES}

[1] Heskestad, G., Kung, H.-C., and Todenkopf, N.F., Air Entrainment into Water Sprays," Technical Report RC-77-TP-7, Factory Mutual Research Corporation, Norwood MA, Nov. 1977.

[2] Yuen, M.C., and Chen, L.W., Heat Transfer Measurements of Evaporating Liquid Droplets, International Journal of Heat and Mass Transfer, Vol. 21, pp. 537-542, 1978.

[3] Yuen, M.C. and Chen, L.W., On Drag of Evaporating Liquid Droplets, Combustion Science and Technology, Vol. 14, pp. 147-154, 1976.

[4] Heskestad, G.H., Sprinkler/Hot Layer Interaction, Technical Report FMRC J. I. OT1N2.RU prepared for National Institute of Standards and Technology, re-issued as NIST-GCR-91-590, National Institute of Standards and Technology, Gaithersburg MD, May, 1991.

[5] Keenan, J.H. and Kaye, J., Gas Tables, Wiley, 1957.

[6] Turner, J.S., Jets and Plumes With Negative or Reversing Buoyancy, Journal of Fluid Mechanics, Vol. 26, pp. 779-792, 1966.

[7] Baines, W.D., Entrainment by a Plume or Jet at a Density Interface, Journal of Fluid Mechanics, Vo1. 68, pp. 309-320, 1975.

[8] Cooper, L.Y., Estimating the Environment and the Response of Sprinkler Links in Compartment Fires with Draft Curtains and Fusible LinkActuated Ceiling Vents - Part I: Theory, NBSIR 88-3734, National Bureau of Standards, Gaithersburg MD, 1988, also (with "Part I:" not in title), Fire Safety Journal 16, pp. 137-163, 1990.

[9] Davis, W.D. and Cooper, L.Y., Estimating the Environment and the Response of Sprinkler Links in Compartment Fires with Draft Curtains and Fusible Link-Actuated Ceiling Vents - Part II: User Guide for the Computer Code LAVENT, NISTIR 89-4122, National Institute of Standards and Technology, Gaithersburg MD, August 1989.

[10] Davis, W.D. and Cooper, L.Y., A Computer Model for Estimating the Response of Sprinkler Links to Compartment Fires With Draft Curtains and Fusible Link-Actuated Ceiling Vents, Fire Technology, pp. 113-127, May 1991. 


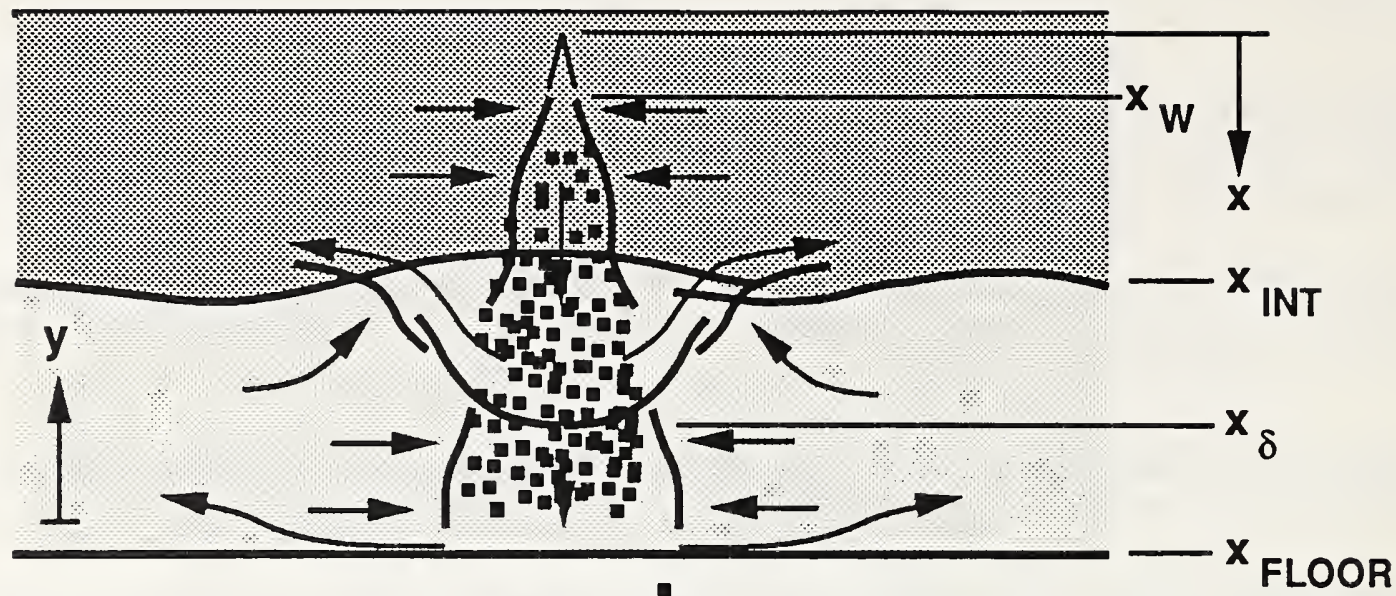

(a) Sprinkler in upper layer, $\mathrm{dM} / \mathrm{dx} \leq 0$ immediately below interface: ICOND 3 or 4

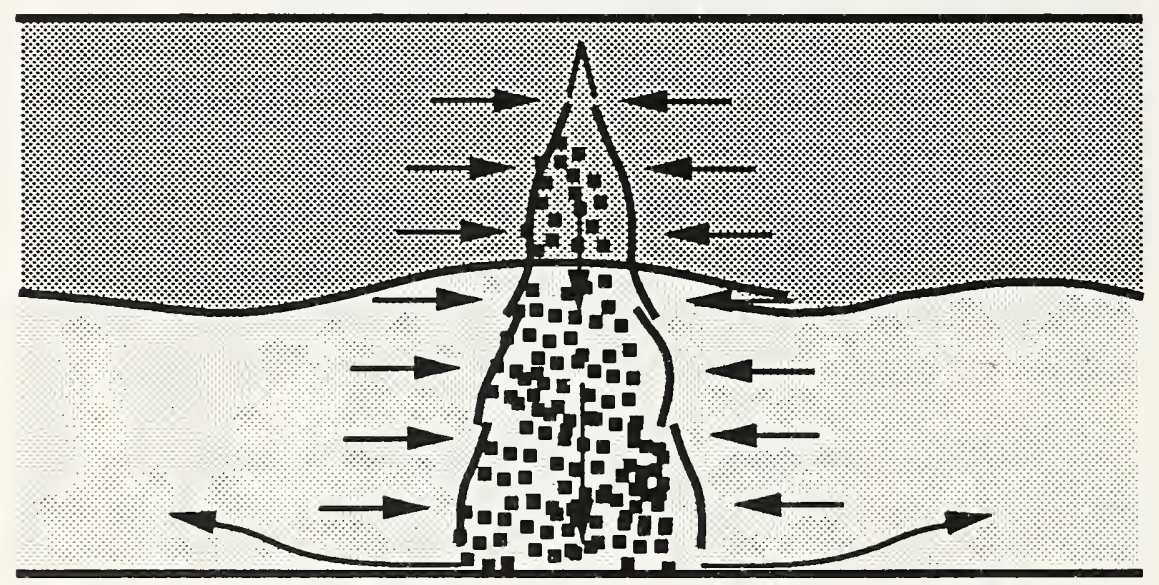

(b) Sprinkler in upper layer, $\mathrm{dM} / \mathrm{dx}>0$ immediately below interface: ICOND 2, 5, or 6

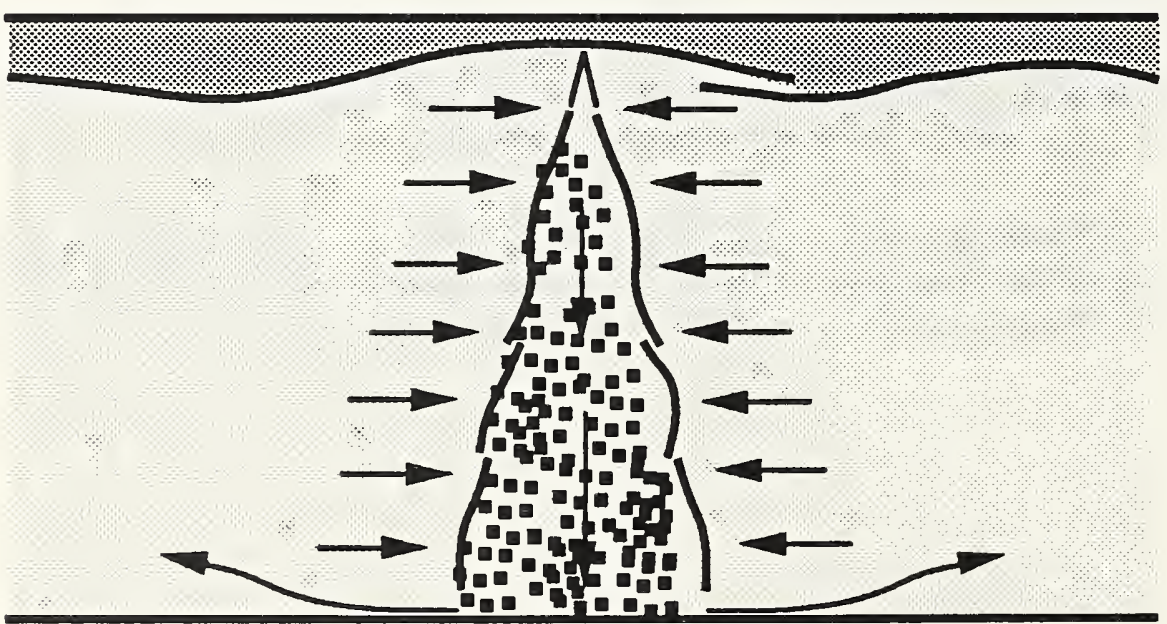

(c) Sprinkler in lower layer, at or below the interface: ICOND 1

Figure 1. The three generic scenarios for interaction of an operating sprinkler and a two-layer fire environment. 

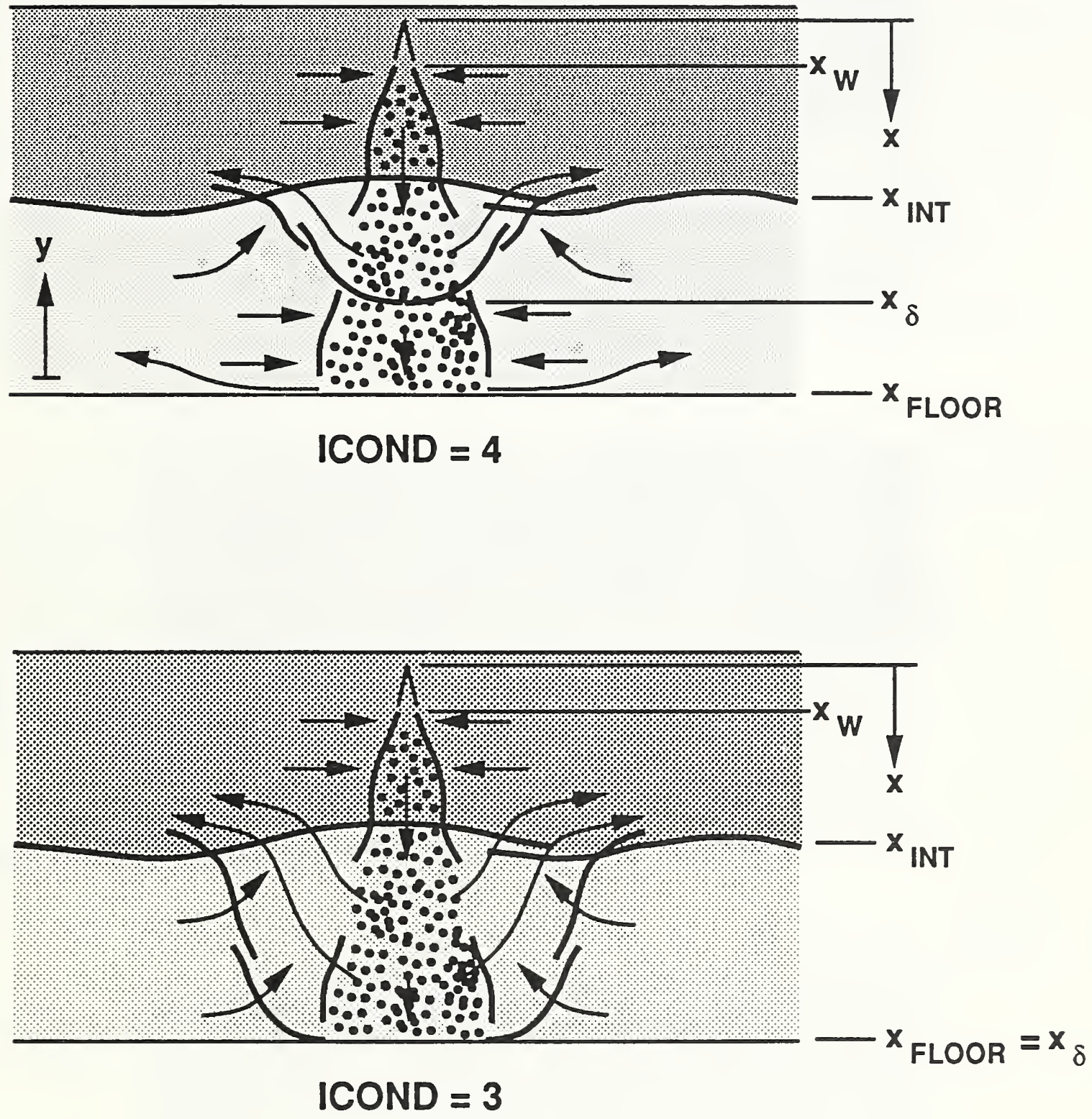

Figure 2. Flow conditions of Figure 1a: ICOND 3 and 4. 

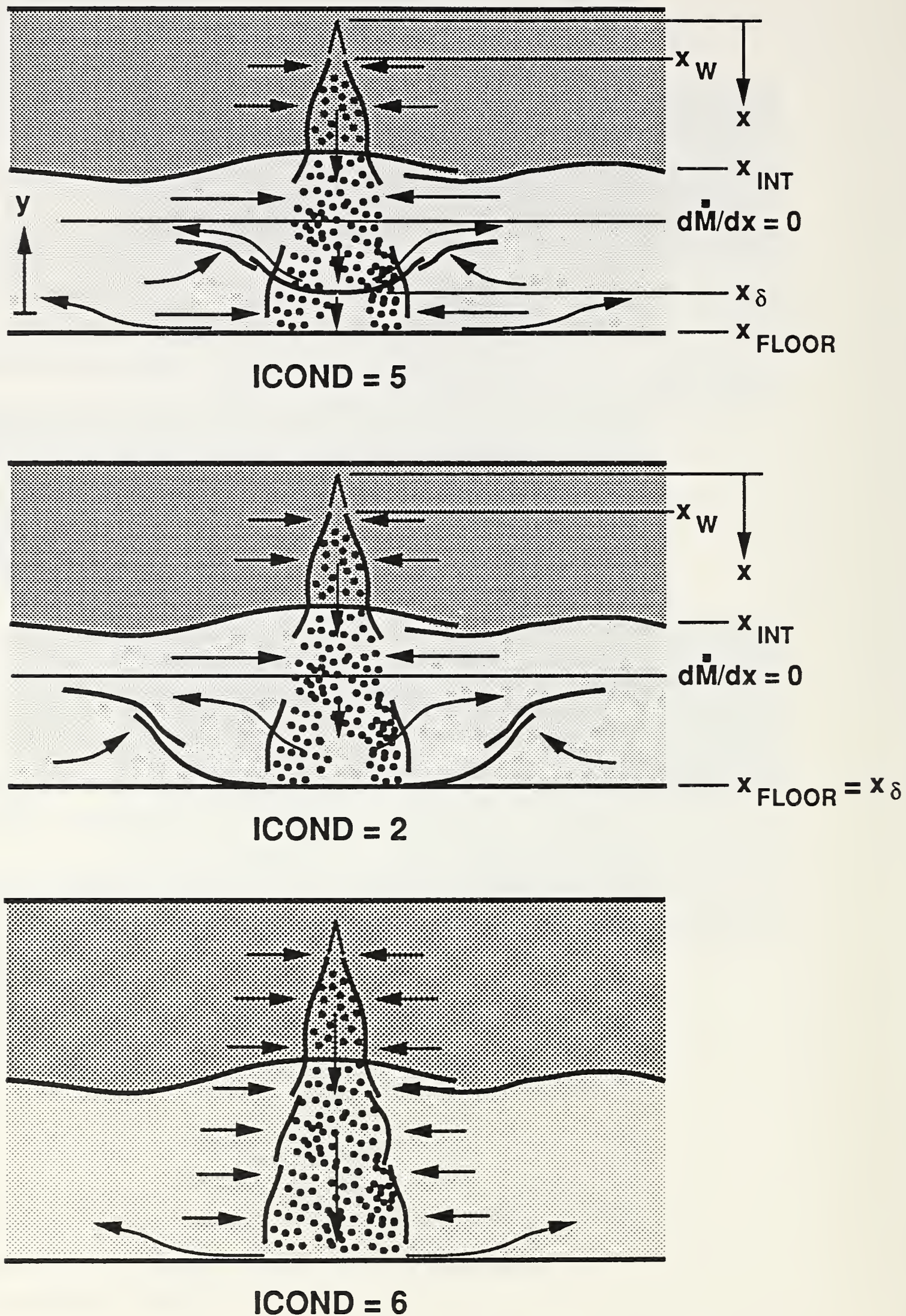

Figure 3. Flow conditions of Figure 1b: ICOND 2, 5, or 6 . 


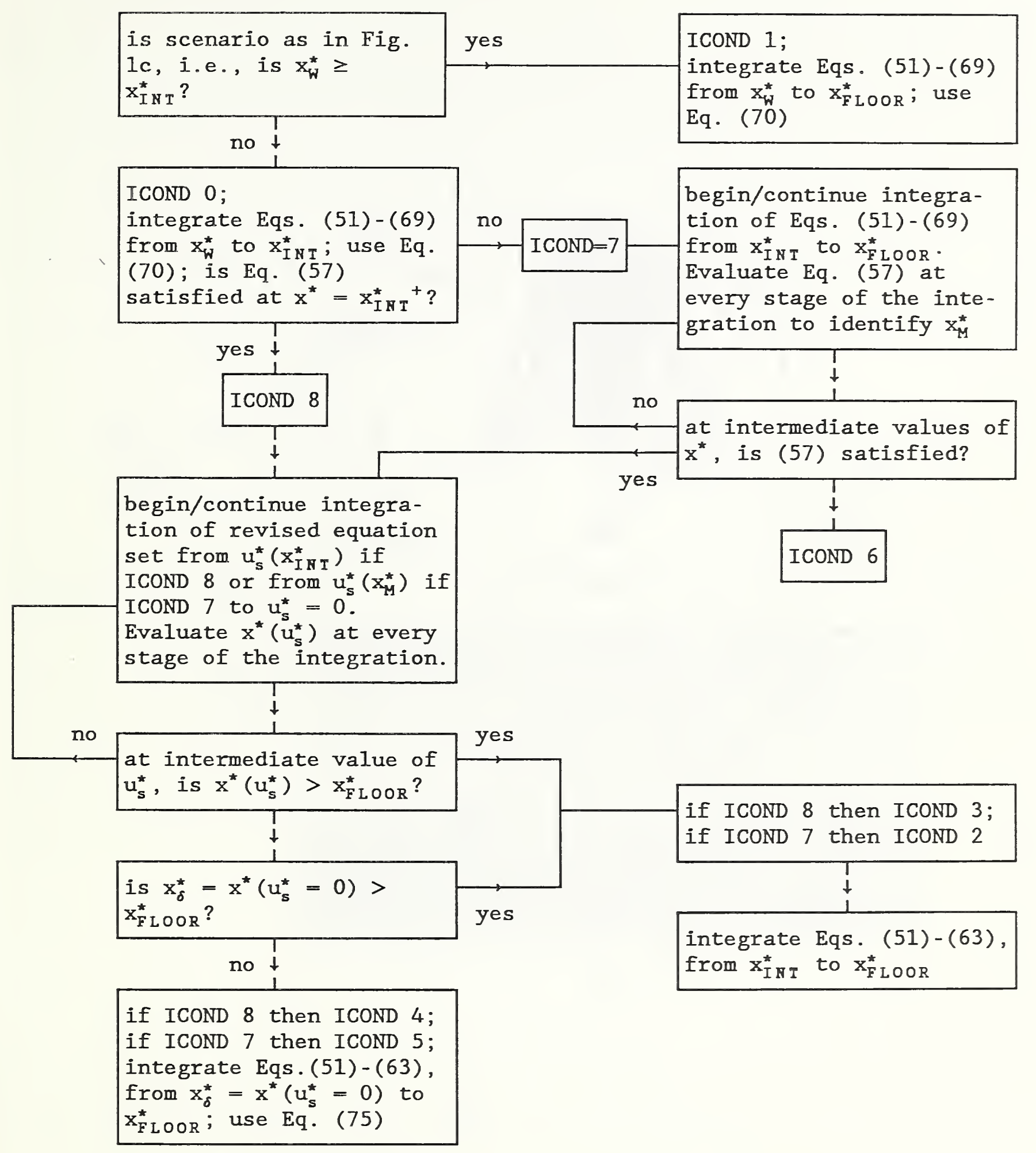

Figure 4. Procedure for solving Eqs. (51)-(65) for $x_{W}^{*} \leq x^{*} \leq x_{\text {LOOR }}^{*}$. 


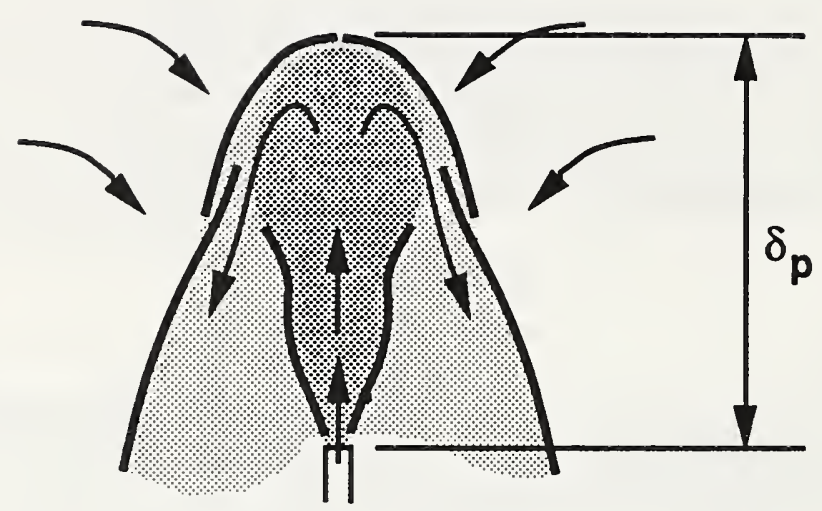

(a)

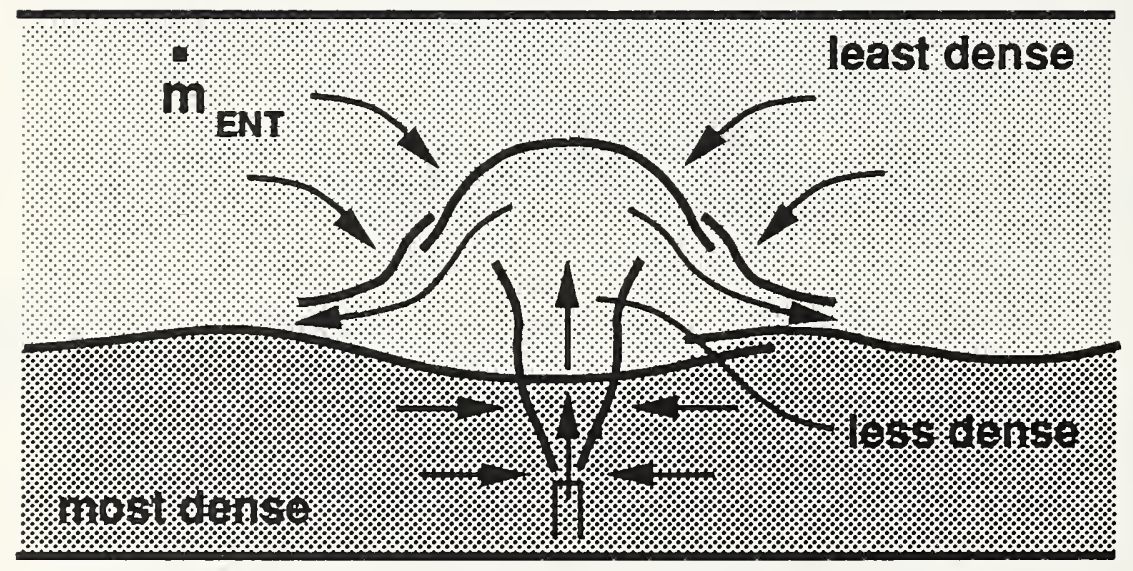

(b)

Figure 5. Experimental studies of jets and plumes with reversed, purely buoyant body forces: a) to determine $\delta_{\mathrm{p}}[6]$; and b) to determine $\dot{\mathrm{M}}_{\mathrm{ENT}}$ [7]. 


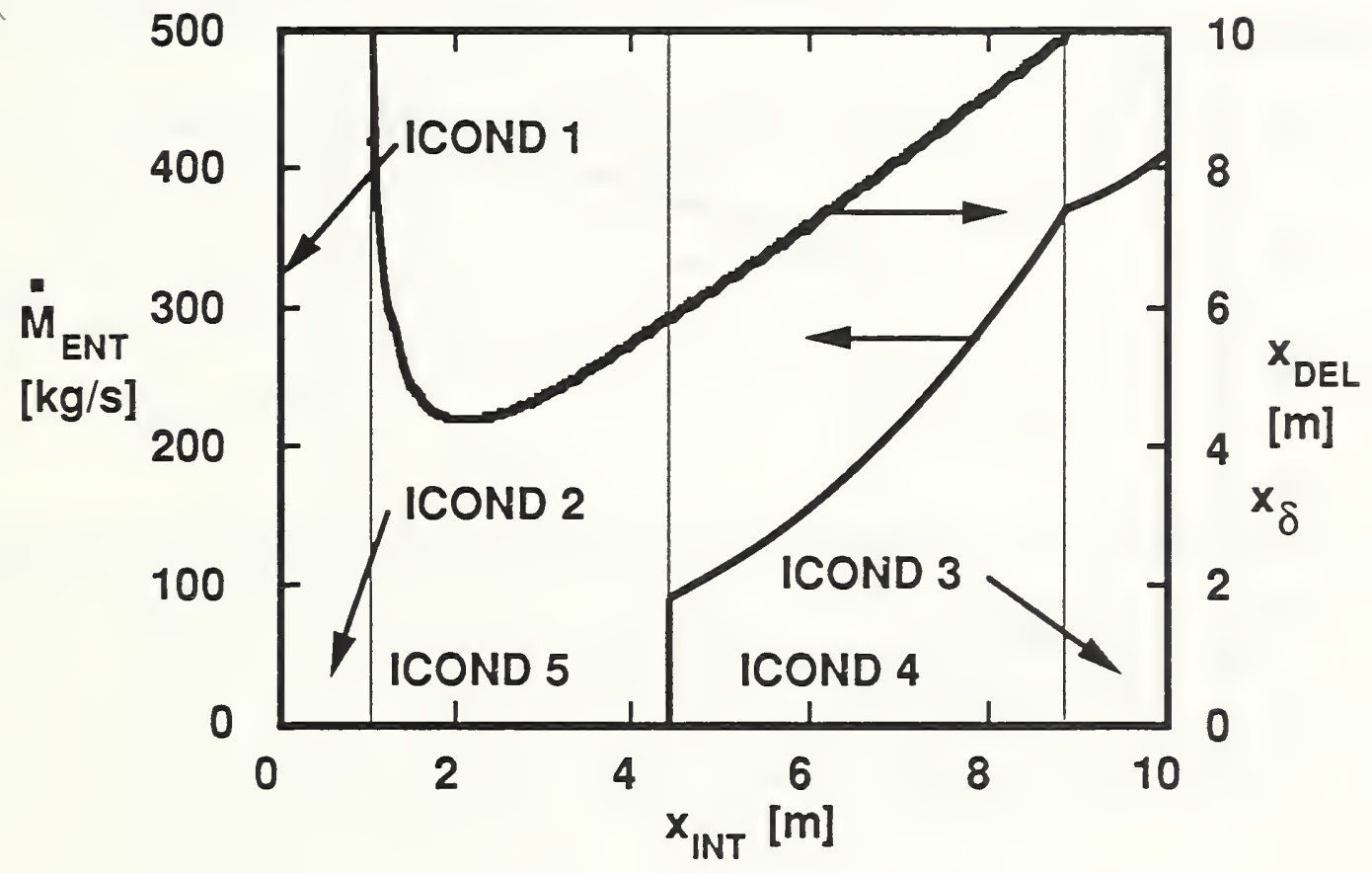

Figure 6. Predictions of $\dot{M}_{E K T}$ and $x_{\delta}$ vs interface elevation for a spray nozzle operating in a two-layer fire environment with a $600 \mathrm{~K}$ upper layer and a $293 \mathrm{~K}$ lower layer. 


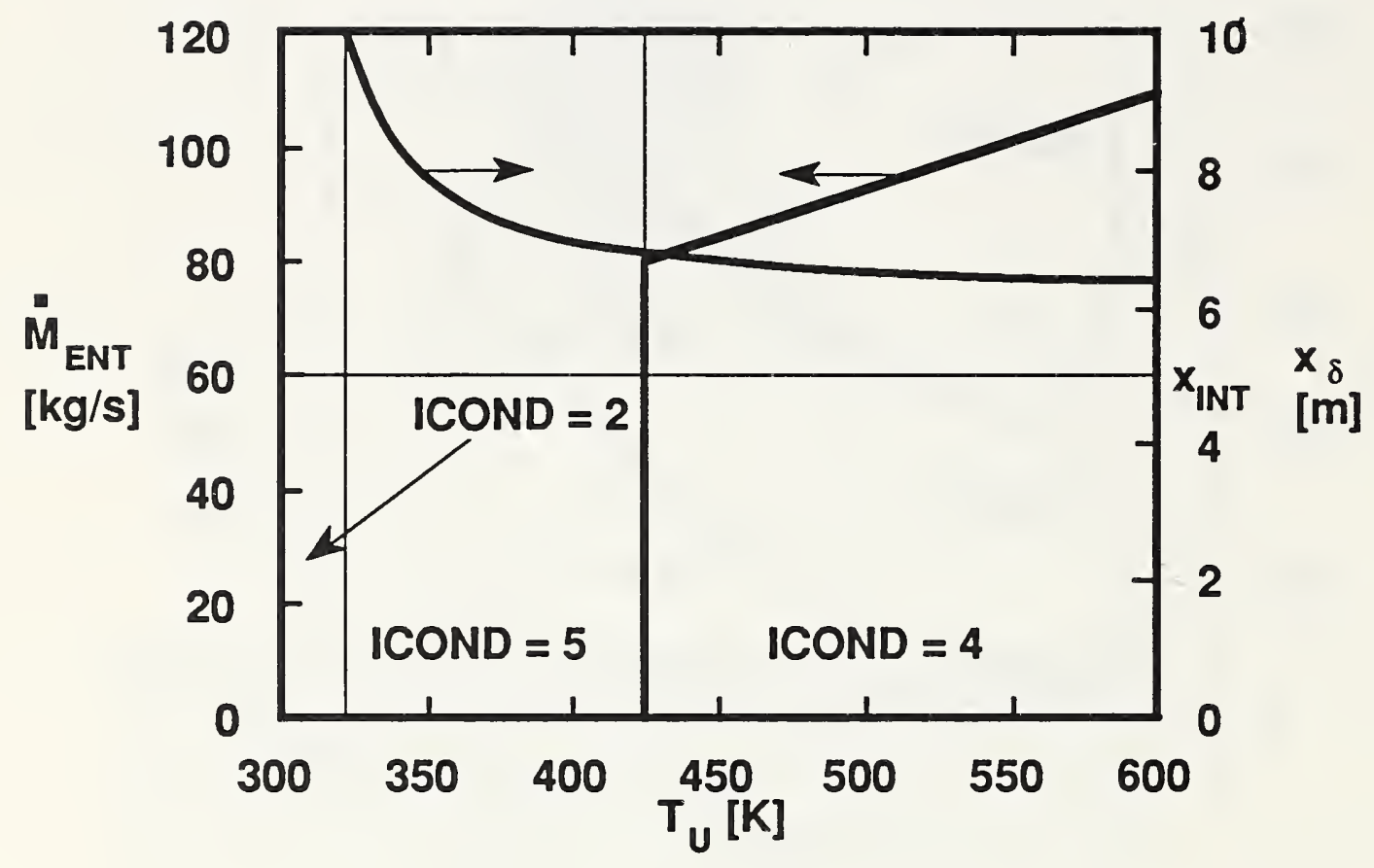

Figure 7. Predictions of $\dot{\mathrm{M}}_{\mathrm{ENT}}$ and $\mathrm{x}_{\delta}$ vs upper layer temperature for a spray nozzle operating above a two-layer fire environment with a $5 \mathrm{~m}$ thick upper layer and a $293 \mathrm{~K}$ lower layer. 


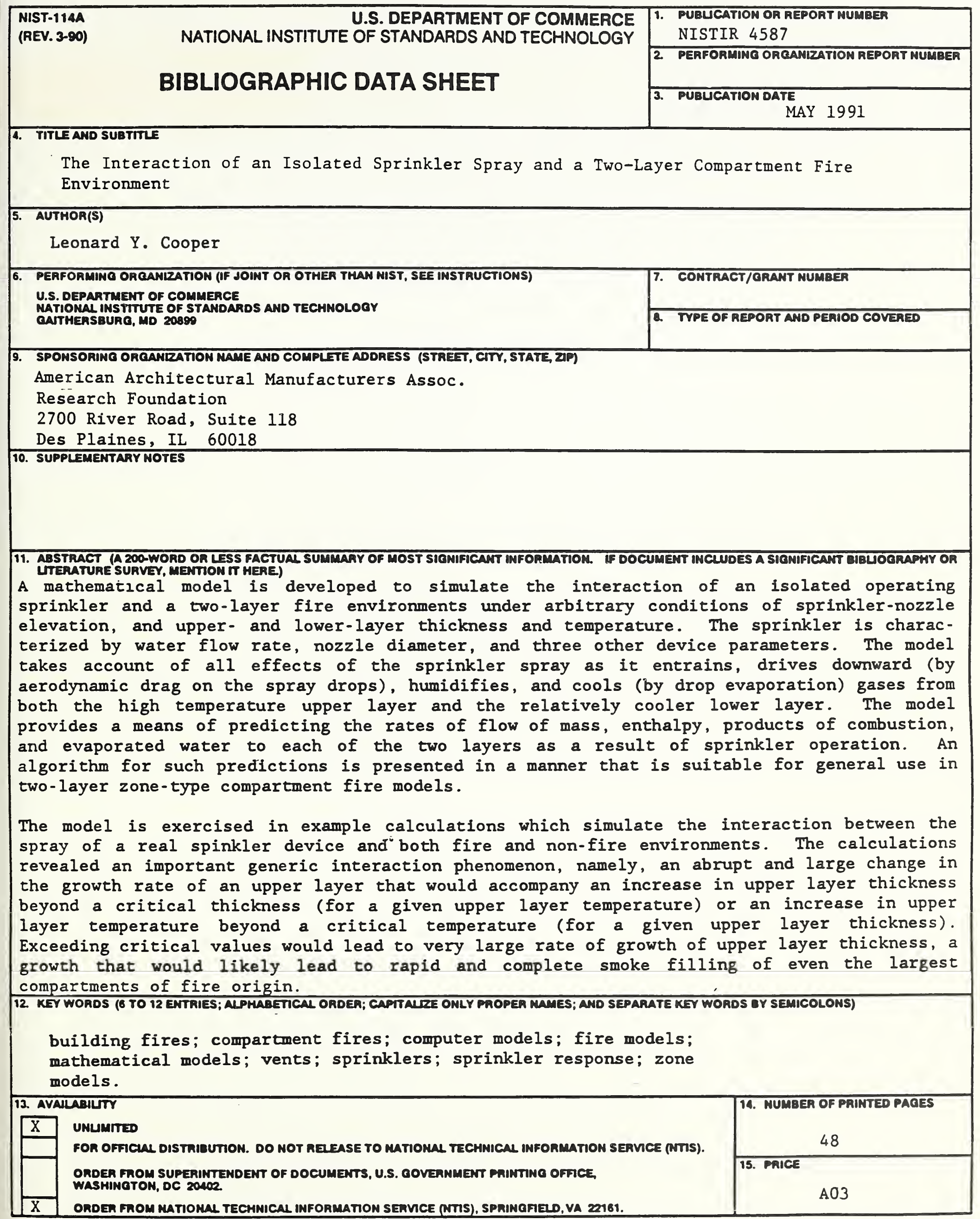



